NBER WORKING PAPER SERIES

\title{
DEFLATION AND THE INTERNATIONAL GREAT DEPRESSION: \\ A PRODUCTIVITY PUZZLE
}

\author{
Harold L. Cole \\ Lee E. Ohanian \\ Ron Leung \\ Working Paper 11237 \\ http://www.nber.org/papers/w11237
}

\author{
NATIONAL BUREAU OF ECONOMIC RESEARCH \\ 1050 Massachusetts Avenue \\ Cambridge, MA 02138 \\ April 2005
}

We acknowledge the support of the National Science Foundation (Cole SES 0137421 and Ohanian SES 0099250). We would particularly like to thank Richard Rogerson for helpful comments and criticisms, as well as Ben Bernanke, Toni Braun, V.V. Chari, Larry Christiano, Pat Kehoe, Narayana Kocherlakota, Jeremy Greenwood, Fumio Hayashi, Ellen McGrattan, and Ed Prescott. We thank Yi-Li Chien, David Lagakos, Casey Otsu and Mauro Rodrigues for research assistance.

(C) 2005 by Harold L. Cole, Lee E. Ohanian, and Ron Leung. All rights reserved. Short sections of text, not to exceed two paragraphs, may be quoted without explicit permission provided that full credit, including $\odot$ notice, is given to the source. 
Deflation and the International Great Depression: A Productivity Puzzle

Harold L. Cole, Lee E. Ohanian, and Ron Leung

NBER Working Paper No. 11237

April 2005

JEL No. E0,N1

\begin{abstract}
$\underline{\text { ABSTRACT }}$
This paper develops the first dynamic, stochastic, general equilibrium analysis of the International Great Depression. We construct a new version of Lucas?s (1972) monetary misperceptions model, with a real shock (productivity) and a nominal shock (money supply). We use the model with a newly assembled panel data set from 17 countries between 1929-33 to quantify the fraction of output change and price change that is accounted for by these two shocks. Data limitations require us to develop a new procedure for identifying the two shocks. The identified productivity shock has a large country-specific component, and is highly correlated with actual productivity. The identified monetary shock has a large common component, and is highly correlated with money supply changes. We find that the model accounts for most of the variation in macroeconomic activity in the panel of countries. About 2/3 of output change is accounted for by the real (productivity) shock, and virtually all of the change in nominal prices is accounted for by the nominal (money supply) shock. The only variable we find that is highly correlated with the productivity shock is stock prices. We conclude that financial friction models are potentially the most promising class of models for understanding the Solow Residual during this period, and thus the Great Depression.
\end{abstract}

Harold L. Cole

Economics Department

University of California

405 Hilgard Avenue

Los Angeles, CA 90095-1477

and NBER

hlcole@econ.ucla.edu

Lee E. Ohanian

8283 Bunch Hall

UCLA, Department of Economics

Box 951477

Los Angeles, CA 90095

and NBER

ohanian@econ.ucla.edu

\section{Ron Leung}

Department of Economics

University of Minnesota

271 19th Avenue South

Minneapolis, MN 55455

rkhleung@econ.umn.edu 


\section{Introduction}

Only recently has the dynamic, stochastic, general equilibrium (DSGE) framework been used to study Great Depressions. These studies, however, have typically focused on a single country, and relatively few countries have been studied. ${ }^{1}$ This paper presents the first DSGE study of the international depression, which allows us to exploit cross-country data to study this worldwide event. Specifically, we study changes in output and prices in 17 countries between 1930 and 1933 in a DSGE model that includes monetary shocks which operate through imperfectly flexible wages, and productivity shocks. We incorporate monetary shocks because there is an empirical cross-country literature that has suggested that deflation combined with imperfectly flexible wages, can account for a significant fraction of the international Depression. We incorporate productivity shocks because much of the DSGE-depression literature has focused on this shock, and has concluded that it is important in understanding the Depression in a few countries, including the U.S. and Canada. This paper considerably expands the scope of DSGE research on the Depression not only by analyzing a panel of countries, but by developing a new model that incorporates both productivity and monetary shocks, by accounting for changes in not just output but also in prices, by testing the model economy in much more detail than is typically done in either the depression or DSGE literature, and by investigating the primitive source of productivity shocks.

We use the model to assess how much of the change in output and in deflation can be accounted for by monetary shocks, and how much by productivity shocks. The relative importance of these two shocks in a panel data setting, and within a DSGE model is a completely open question, because monetary shocks have been excluded from several DSGE single-country analyses, and because the cross-country literature has not used DSGE models. Thus, studying the contribution of these two shocks is the natural starting point for any DSGE analysis of the international Depression as they represent the canonical demand (nominal) and supply (real) shocks that have been proposed for understanding this episode.

Our main finding is that productivity accounts for most of the change in output in the 17-country panel, while monetary shocks account for virtually all of the change in prices. Given the importance of productivity in accounting for output in the growth model, we investigate the source of these productivity shocks. We find that the most promising avenue for understanding the source of these productivity shocks is through financial shocks, as there

\footnotetext{
${ }^{1}$ Studies for the U.S. include Crucini and Kahn (1996), Cole and Ohanian (1999), Bordo, Erceg and Evans (2000), Cole and Ohanian (2004), Harrison and Weder (2005), and Chari, Kehoe, and McGrattan (2006). Kehoe and Prescott (2002)'s edited volume include studies of 4 other countries (Canada, France, Germany, and Italy).
} 
is a very high correlation between productivity and real stock prices. Other explanations of the productivity shocks, including capacity utilization or labor hoarding operating through either deflation, money, or exchange rates are inconsistent with the data.

The data for the 17 country panel are compiled from a number of sources, including very recent measures for some of the countries. The dataset thus provides the most up-to-date measures of international macroeconomic data for the interwar period. Section 2 statistically summarizes the data, including the relationships between output, deflation, productivity, and real wages. The key feature from this summary is that productivity is strongly related to output, but deflation is only weakly related to output.

Section 3 presents the model economy. A new and quantitatively important feature of the model is that the monetary nonneutrality is due to an information imperfection, as in Lucas (1972). There is a range of values for the nonneutrality of money in our model, and this variable nonneutrality is central for conducting the quantitative analysis and evaluating the robustness of the results. Moreover, our model provides a simple way of introducing the Lucas misperceptions feature into a fully-specified GE model with capital. The Lucas non-neutrality has otherwise been largely excluded from the DSGE literature.

Section 4 discusses the quantitative procedures. Data limitations require us to develop new procedures for constructing the shocks and for assessing the empirical validity of the model and of the decomposition of output and deflation into orthogonal productivity and monetary components. Regarding the shocks, we treat total factor productivity (TFP) as a latent variable because we do not have capital stocks and/or economy-wide labor for a number of countries, and, as is standard, we also treat money shocks as a latent variable. In particular, we construct the monetary and productivity shocks so that the model economy exactly reproduces output and deflation in each country and for each year between 1929-33. We then assess the empirical plausibility of the analysis by comparing the time paths of model variables to those in the data. We then account for the fractions of output and price changes due to productivity and monetary shocks.

Section 5 compares the model variables to the actual variables, and shows that there is a close conformity between the model and the data, as the model accounts for between 70-90 percent of the changes in productivity, money, consumption, and labor. Section 6 presents the decomposition results, and evaluates the robustness of this decomposition by comparing the model-based output decomposition to a statistically-based output decomposition, and find that they are almost identical.

Given the importance of productivity, section 7 tests various hypotheses about these shocks to gain a deeper understanding of them. Specifically, some classes of models with financial shocks or with trade shocks are observationally equivalent to productivity shocks in 
a stochastic growth model. To identify whether financial and/or open economy models with these alternative shocks are promising for understanding productivity and the Depression, we test whether the productivity shocks can be explained by financial and trade-related variables, including deflation, nominal and real interest rates, real exchange rates, various monetary aggregates, a measure of banking panics, and the real value of the stock market. Real stock prices are the only one of these variables that explain a substantial fraction of the productivity shocks. Simulating our model with the productivity component explained by the stock market, and with the monetary shocks, accounts for 73 percent of real output change and 94 percent of price change in the panel of countries. These findings on the real output change indicate that the most promising factor for jointly understanding productivity change and the international Depression is a financial factor that affects real share prices and productivity.

Section 8 compares our findings to other DSGE studies of the Great Depression, and section 9 concludes.

\section{Data Summary and Its Implications for Modeling}

This section summarizes the data for our 17 country panel. We selected the countries on the basis of consistent availability of data on real GNP and the GNP deflator. Output is real GNP divided by its 1929 value, and deflation is measured as the annual log change in the GNP deflator. We also have compiled a number of other variables, including a wage index, a labor index, a stockmarket index, industrial production, the exchange rate, nominal interest rates, measures of the money supply, and the consumer and producer price indexes for most countries. There are several primary sources for the data and we have used the most recently constructed data. ${ }^{2}$ The Appendix describes the data and the sources.

This section summarizes the output and deflation data that are the focus of the analysis. We use the data to first assess whether a single-factor (single shock) model can primarily account for both deflation and output, or whether a multi-factor approach is required. This is an important first step as we need to choose the number of shocks to include in a model economy. We make this assessment of a single vs. multi-shock model by evaluating whether a single-shock model is consistent with the output and deflation data. If it is, this is interesting in its own right, and it would lead us to restrict our attention to a single shock model.

\footnotetext{
${ }^{2}$ The countries are Australia, Austria, Canada, Czechoslovakia, Denmark, Finland, France, Germany, Hungary, Italy, Japan, the Netherlands, Norway, Sweden, Switzerland, the U.K., and the U.S. For all of these countries were able to gather data on GDP or GNP and the deflator; with the exception of Czechoslovakia where we used the CPI as the price measure.
} 
To make this evaluation, we exploit the fact that in a log-linear framework, a single-factor model implies that deflation, $\pi_{i t}$, and output, $y_{i t}$, will (1) will be highly correlated, and (2) will have idiosyncratic components (and the common components) that will be of similar size. To see this clearly, note that the simplest single-factor model for these variables is given:

$$
\begin{aligned}
y_{i t} & =\bar{x}_{t}+\chi_{i t} \\
\pi_{i t} & =\eta\left(\bar{x}_{t}+\chi_{i t}\right),
\end{aligned}
$$

where $\chi$ is the idiosyncratic component, and $\eta$ is a normalization coefficient ${ }^{3}$. We first decompose output and deflation into their sample mean idiosyncratic (country-specific) components:

$$
\begin{aligned}
y_{i t} & =\bar{y}_{t}+\varepsilon_{i t} \\
\pi_{i t} & =\bar{\pi}_{t}+\xi_{i t}
\end{aligned}
$$

We then calculate the correlation and the relative sizes of common and idiosyncratic components to assess whether the following properties hold:

$$
\operatorname{corr}(\mathbf{y}, \boldsymbol{\pi})>>\mathbf{0}, \frac{\sum \varepsilon_{i t}^{2}}{\sum y_{i t}^{2}} \approx \frac{\sum \xi_{i t}^{2}}{\sum \pi_{i t}^{2}}, \frac{\sum \bar{y}_{t}^{2}}{\sum y_{i t}^{2}} \approx \frac{\sum \bar{\pi}_{t}^{2}}{\sum \pi_{i t}^{2}} .
$$

Table 1 shows the correlation and relative size statistics for output and deflation for the depression (1930-33), which is the period which we analyze, and for the recovery (1934-38), which is the focus of much of the empirical literature. We begin with the data from 1930-33. The main finding is that the data do not support a single factor model. Specifically, the correlation between output and deflation is low or negative during several of the years in the 1930s, and the relative size of the idiosyncratic component of output is much larger than that for deflation. Table 2 extends this analysis by constructing these statistics for the cumulative changes in deflation and output between 1929-32. ${ }^{4}$ The relationship between the cumulative changes of output and deflation are similar to those presented in Table 1; output and prices are uncorrelated (the correlation is -0.01 ), and the idiosyncratic component of output (55

\footnotetext{
${ }^{3}$ This simple model implies the two random variables are the same stochastic process, with a correlation of 1 and the exact same relative size of the common and idiosyncratic components. Of course, this singularity is broken by adding measurement error.

${ }^{4}$ We picked the period up through 1932 because almost all of the countries in the panel remained depressed through at least this year.
} 
percent) is much larger than that of deflation (18 percent). This means that countries had relatively similar deflations, but had dissimilar output changes.

These data indicate that a factor with a large common component is responsible for deflation, and a factor with a large idiosyncratic component is responsible for output. The findings also suggest that deflation will have limited explanatory power in a regression of output on deflation, not only because the correlation is low, but because the size of the idiosyncratic component is so different between $y$ and $\pi$.

To demonstrate this, we fit a series of regressions that approximate various classes of log-linearized business cycle models in which deflation impacts output. In all cases, the explanatory power of deflation is low.

Output change in any log-linearized DSGE model which (i) abstracts from capital, and (ii) in which deflation is the only shock, can be written as $y_{t}=\alpha \pi_{t}$, where $y_{t}$ is the logdeviation of output from its steady-state value, $\pi_{t}$ is the log of the change in the GNP deflator between $t-1$ and $t$, and $\alpha$ is the parameter governing the impact of log price change on output. We estimate this equation using ordinary least squares (OLS). Deflation explains 23 percent of the sum of squared output deviations. ${ }^{5}$ The second regression adds lagged deflation to account for possible delayed impact of price change. ${ }^{6}$ The addition of lagged deflation increases the explanatory power from 23 percent to just 29 percent. The reason that lagged values of deflation do not account for output is the same as why contemporaneous deflation doesn't: lagged deflation is not highly correlated with output, and lagged deflation has a much larger common component than output.

We next add a constant term to both of the above regressions as a simple proxy for an omitted factor to see if that changes the results. All of the deflation regressors are statistically insignificant when a constant term is included. We then estimated a third regression with country-specific deflation coefficients to see if allowing for heterogeneity in the deflation response raises the importance of deflation. We therefore estimated $y_{i t}=\alpha_{i}+\beta_{i} \pi_{i t}+\varepsilon_{i t}$, which includes a country-specific constant term to allow for country fixed effects which is a proxy for omitted country-specific factors. The deflation coefficients are jointly insignificant in this regression. ${ }^{7}$ In summary, output has a much larger idiosyncratic component than deflation, a much smaller common component than deflation, and neither contemporaneous

\footnotetext{
${ }^{5}$ The explanatory power of deflation in this equation is an upper bound because we place no economic restrictions on the size of the parameter $\alpha$, and because we abstract from using instruments for deflation.

${ }^{6}$ We do not report additional lags of logged price change in the regression because for most countries price levels were very similar between 1927 and 1928, as well as between 1928 and 1929. Deflation typically began in 1929 or afterwards.

${ }^{7}$ We also estimated a fourth regression with both contemporaneous and lagged deflation, with countryspecific coefficients and fixed effects. The deflation coefficients were also insignificant.
} 
nor lagged deflation can account for much of output during the Depression.

The relationship between real wages and output provides further evidence that accounting for output requires a factor other than deflation. Table 3 shows the correlation between real wages and output is positive in each year, through 1933, ranging between .28 and .48, and only becomes substantially negative beginning in 1936. In contrast, the deflation- sticky wage hypothesis implies a negative relationship between real wages and output. Taken together, these findings indicate that jointly accounting for output and deflation in the 1930-33 period in a log-linear model requires a multifactor approach. Moreover, the results presented here indicate that the factor driving output has a large idiosyncratic component, and is a labor demand shifter, as the correlation between real wages and output is positive.

We now compare the relationship between output and the real wage to those presented in cross-country empirical studies of the 1930s: Bernanke and Carey 1996, and Eichengreen and Sachs 1985. We discuss this in detail in the appendix, and we summarize the comparison here. There are two key differences. One is regarding the time period, as we use data from the Depression years (1930-33), while Eichengreen and Sachs use data just from the recovery (1935), and Bernanke and Carey (1996) used data from 1931-1936, which includes some of the depression years and several of the recovery years. ${ }^{8}$ The other difference is in terms of measurement, as the other studies uses industrial production for output and a wholesale price index instead of the GNP deflator. These other studies report a negative relationship between IP and the nominal wage index deflated by the WPI, which stands in contrast to our findings of a positive relationship between real GNP and the nominal wage deflated by the GNP deflator.

We assess the source of these differences, and find that they are primarily due to the difference in the period of analysis. Table A2 in the appendix presents the correlation between wages deflated by the wholesale price index, and alternatively by the consumer price index, and industrial production for the 1930-37 period. The correlations between these variables are similar to the correlation between real GNP and the wage divided by the GNP deflator. For example, all of the correlations are positive in 1930 and 1931, and are quite negative in 1936 and 1937. Regarding the differences in measurement between our study and the others, the appendix discusses in detail why the GNP deflator or the CPI are better price indexes to use to deflate the wage than the WPI, which was used in Bernake and Carey (1996) and Eichengreen and Sachs (1985). This comparison shows that the findings

\footnotetext{
${ }^{8}$ Choudri-Kochin (1980) is a well-known paper but is not comparable to our analysis. They do not report correlations betwen output and prices or output and wages, but rather focus on the extent that output in 8 countries tended to be related to U.S. output, and whether prices in these countries were related to U.S. prices. However, our analysis does include most of the countries analyzed by Choudri and Kochin.
} 
reported in these other studies do not have important implications for our analysis of the 1930-33 period. ${ }^{9}$

We now assess the relationship between productivity and output and find that the two variables are similar. Figure 1 shows the log changes in output and productivity between 1930-33 for the seven countries for which we can construct aggregate productivity. We have economy-wide total factor productivity (TFP) for five countries (Canada, France, Germany, the United Kingdom, and the United States) and economy-wide labor productivity for two other countries (Australia and Japan). The figure shows a systematic relationship between productivity and output: the countries with large depressions (Canada, France, Germany, and the United States) had large productivity declines, and the countries with mild depressions or expansions (Australia, Japan, and the United Kingdom) did not have these large productivity declines. The overall correlation of the two variables is 0.90 .

These data suggest that productivity may be a key factor in accounting for output. The positive relationship between real wages and output provides further evidence that productivity is a potentially important shock. This positive correlation requires that one of the shocks in the model needs to be a labor demand shifter, and a productivity shock satisfies this requirement.

Given these findings, the following section develops a model economy with two shocks productivity shocks and monetary shocks - to see if it can plausibly account for both deflation and output in the panel dataset. The model will feature nonneutral monetary shocks operating through sticky nominal wages, as suggested by the deflation literature. We will use the model to determine the relative importance of each shock in accounting for deflation and output. In anticipation of the finding that productivity will be important, we note here that we will extend our analysis beyond the standard approach in the RBC literature that treats productivity shocks as a purely exogenous process. Instead we will interpret productivity shocks as the possible consequence of other economic factors. In particular, some classes of models with financial intermediation and/or international trade are observationally equivalent to a one-sector growth model with productivity shocks (for example, see Chari, Kehoe, and McGrattan (2006), Backus and Crucini (2000), and Crucini and Kahn (2006)). We therefore will test if the productivity shocks are significantly related to various financial and

\footnotetext{
${ }^{9}$ This change in the correlation between output and wages in the mid-late 1930s raises the possibility that monetary forces/sticky wages may account for more of the recovery than the Depression, though testing this hypothesis requires much more work and thus is well beyond the scope of this paper. This is not only because the correlation is not a structural relationship, but because the correlations do not control for other variables, such as productivity, and government policy changes that were adopted in many countries at the mid-1930s. For example, Cole and Ohanian (2004) and Fisher and Hornstein (2002) argue that labor market policies - not monetary policies - significantly affected post-Depression real wages in the U.S. and Germany, respectively.
} 
trade variables. This extended analysis is the first step towards identifying promising classes of deeper models for understanding the International Depression.

\section{The Model}

To develop the model, we follow the literature that proposes the monetary nonneutrality operated through imperfectly flexible nominal wages. We introduce nominal wage inflexibility using an information imperfection in the spirit of Lucas (1972). In our model, households choose labor supply without full information; they know the nominal wage when choosing their labor supply, but they don't know the price level; thus they face a signal extraction problem when choosing labor supply. Our model brings the Lucas misperceptions paradigm into the quantitative DSGE literature, which otherwise has largely ignored the Lucas model due to the computational difficulties associated with the islands formulation. Our formulation is simple, as it does not use an islands environment. ${ }^{10}$

With a log-linear approximation, our model is qualitatively identical to a standard predetermined wage model, but our model provides an information-theoretic foundation for sticky wages and is a better quantitative tool for studying the Depression than a standard predetermined wage model, as the nonneutrality of money is too large in this latter model. The information-theoretic mechanism provides a deeper foundation for wage rigidity, and quantitatively this model is preferable to a standard predetermined wage model. Specifically, the standard predetermined wage model generates a depression that is much too large for almost every country when the model is simulated with just monetary shocks that generate the observed deflation rate. This implies that the standard sticky wage model requires large positive productivity shocks to offset the impact of deflation and be able to account for output change in the Depression. (These issues are detailed in section 4).

Therefore a model which has a smaller nonneutrality is required. Our misperceptions model satisfies this requirement, and moreover, the nonneutrality in our model takes on a range of values, just as it does in the Lucas (1972) model. This is important because it allows us to choose a nonneutrality value that is quantitatively plausible for the analysis, and also lets us assess whether the decomposition results are sensitive to different values of the nonneutrality. ${ }^{11}$

\footnotetext{
${ }^{10}$ Chari, Kehoe, and McGrattan (2006), Cole and Ohanian (2002), and others have shown that accounting for the U.S. Depression requires a model with a "productivity wedge" and a "labor wedge". Our model will generate both of these wedges. Moreover, though the model does not account for the details of high wages stressed in the cartelization studies of Cole and Ohanian (2004) and Ohanian (2006), it can roughly capture the high wage mechanism through the simple sticky wage channel.

${ }^{11}$ We could have reduced the size of the nonneutrality in the pre-determined wage model either by short-
} 
To conserve space, we present the main equations of the model. There is a large number of identical households who have preferences over sequences of a cash good, a credit good, and leisure. We normalize the size of the population to one. Preferences are given by

$$
E \sum_{t=0}^{\infty} \beta^{t}\left\{\log \left(\left[\alpha c_{1 t}{ }^{\sigma}+(1-\alpha) c_{2 t^{\sigma}}\right]^{1 / \sigma}\right)+\phi \log \left(1-n_{t}\right)\right\},
$$

where $c_{1}$ is the cash good, $c_{2}$ is the credit good, and $1-n$ is non-market time. The household maximizes (1) subject to a wealth constraint and a cash-in-advance (CIA) constraint:

$$
\begin{gathered}
m_{t}+w_{t} n_{t}+r_{t} k_{t}+\left(T_{t}-1\right) M_{t} \geq m_{t+1}+p_{t}\left[c_{1 t}+c_{2 t}+k_{t+1}-(1-\delta) k_{t}\right], \\
p_{t} c_{1 t} \leq m_{t}+\left(T_{t}-1\right) M_{t} .
\end{gathered}
$$

Nominal wealth is the sum of initial cash holdings $m_{t}$, labor income $w_{t} n_{t}$, capital income $r_{t} k_{t}$, and a lump-sum monetary transfer from the government $\left(T_{t}-1\right) M_{t}$, where $T_{t}$ is the gross growth rate of the money stock. The household finances cash carried forward, $m_{t+1}$ and purchases of cash goods, credit goods, and investment $\left(p_{t}\left[c_{1 t}+c_{2 t}+k_{t+1}-(1-\delta) k_{t}\right]\right)$. Output is given by:

$$
Y_{t}=Z_{t} K_{t}^{\theta} N_{t}^{1-\theta}
$$

where $Z$ is a technology shock that follows a first-order lognormal autoregressive process:

$$
Z_{t}=e^{\hat{z}_{t}}, \hat{z}_{t}=\rho_{z} \hat{z}_{t-1}+\varepsilon_{z t}, \varepsilon_{z t} \sim N\left(0, \sigma_{z}^{2}\right) .
$$

The resource constraint is

$$
C_{1 t}+C_{2 t}+X_{t} \leq Y_{t}
$$

The transition rule for capital is

$$
K_{t+1}=(1-\delta) K_{t}+X_{t} .
$$

Monetary policy is given by exogenous changes in the gross growth rate of money. ${ }^{12}$ The

ening the length of the period in which wages are fixed or by constructing a multisector model in which only some wages are fixed. Both of these approaches, however, are complicated. The first approach is complicated because the data are available on only an annual frequency. The second approach is complicated because it requires constructing an explict multisector model and dealing with a host of sectoral issues. Our misperceptions model is simpler to use than either of these alternatives, and also provides a deeper theoretical foundation for sticky wages.

${ }^{12}$ Our specification of exogenous, contractionary monetary shocks is consistent with the view stressed in the International Depression literature that deflation was caused by exogenous monetary shocks resulting 
money stock follows a first-order lognormal autoregressive process:

$$
T_{t}=\bar{\tau} e^{\hat{\tau}_{t}}, \text { where } \hat{\tau}_{t}=\rho_{\tau} \hat{\tau}_{t-1}+\varepsilon_{\tau t}, \varepsilon_{\tau t} \sim N\left(0, \sigma_{\tau}^{2}\right)
$$

The change in the money stock at the beginning of the period is thus equal to $\left(T_{t}-1\right) M_{t}$, and the total money stock at the beginning of the period is: $M_{t+1}=T_{t} M_{t}$

We now describe the timing of information and transactions. Define the state of the economy by $S_{t}=\left(K_{t}, \hat{z}_{t-1}, \hat{\tau}_{t-1}, \varepsilon_{t}^{z}, \varepsilon_{t}^{\tau}\right)$. The lagged values of the shocks and their current innovations are included separately because the model requires that households choose labor supply before they observe $\left(\varepsilon_{t}^{z}, \varepsilon_{t}^{\tau}\right)$. There are two sub-periods. In the initial sub-period, the household knows its own state $\left(k_{t}, m_{t}\right)$, knows a subset of the state vector which we denote by $\bar{S}_{t}=\left(K_{t}, \hat{\tau}_{t-1}, \hat{z}_{t-1}\right)$, and knows the nominal wage. Households do not know the realizations of the money supply or technology innovations, while the representative firm knows the full state vector. ${ }^{13}$ The labor market opens, and the household and firm make their labor market choices. Note that households choose labor supply without knowing the full state vector.

In the second sub-period, the full aggregate state $\left(S_{t}\right)$ is revealed, households receive their monetary transfer from the government, workers rent capital to the firm, output is realized, and households acquire cash consumption goods, credit consumption goods, and investment goods. The firm's maximization problem is standard:

$$
\max _{K_{t}, N_{t}} p_{t} Z_{t}\left(K_{t}\right)^{\theta}\left(N_{t}\right)^{1-\theta}-w_{t} N_{t}-r_{t} K_{t}
$$

To construct a recursive formulation, we denote the law of motion for aggregate capital by $H\left(S_{t}\right)$, and we divide all date $t$ nominal variables by $M_{t-1} T_{t-1}$. This implies that the normalized beginning of period aggregate money stock is one $\left(m_{t}=1\right)$. This stationaryinducing transformation yields the following relationship between the quantity of money chosen by the household in period $t\left(\tilde{m}_{t+1}\right)$ and the quantity of money that the household

from the gold standard (see Bernanke (1995) and Eichengreen (1992)).

${ }^{13}$ These assumptions about the household's information set and the firm's information set are natural to make in this environment, given that we are using this simple environment to stand in for a richer environment in a multisector model producing heterogeneous consumer goods. In such an environment, firms only care about only four variables in the model: their product price, the state of their technology, and the rental prices of labor and capital. It seems plausible that the firm would know a lot about these variables just prior to production. The households in such an environment would care about many more variables than a firm would. In particular, the household would care about the entire distribution of prices in the economy. It seems plausible that households would have only imperfect information about the entire distribution at the start of the period. To match the larger informational frictions faced by households within our simple model, we assume that firms know the full state vector, which implies they know their technology and the prices, while households do not know the current shocks. 
has at the start of period $t+1\left(m_{t+1}\right)$ :

$$
m_{t+1}=\tilde{m}_{t+1} / T_{t}
$$

This transition rule implies that the money stock is constant over time, and we denote this constant stock as $M$. We use this transition equation in the household's budget constraint below, substituting $T_{t} m_{t+1}$ for $\tilde{m}_{t+1}$.

The representative household has a two-stage maximization problem. The Bellman equation for the household is given by

$$
\begin{aligned}
& V\left(m_{t}, k_{t}, \bar{S}_{t}, w_{t}\right)= \\
& \max _{n_{t}} E_{\left(\bar{S}_{t}, w_{t}\right)}\left\{\begin{array}{c}
\max _{c_{1 t}, c_{2 t}, m_{t+1}, k_{t+1}} \log \left(\left[\alpha c_{1 t}{ }^{\sigma}+(1-\alpha) c_{2 t}{ }^{\sigma}\right]^{1 / \sigma}\right)+\phi \log \left(1-n_{t}\right) \\
+\beta E_{S_{t}} V\left(m_{t+1}, k_{t+1}, \bar{S}_{t+1}, w_{t+1}\right)
\end{array}\right\}
\end{aligned}
$$

subject to

$$
\begin{gathered}
m_{t}+w_{t} n_{t}+r_{t} k_{t}+\left(T_{t}-1\right) M \geq m_{t+1} T_{t}+p_{t}\left[k_{t+1}-(1-\delta) k_{t}+c_{1 t}+c_{2 t}\right] \\
m_{t}+\left(T_{t}-1\right) M \geq p_{t} c_{1 t}
\end{gathered}
$$

and subject to the stochastic processes for the shocks. In the first stage maximization, the household chooses its labor supply, given $\bar{S}_{t}$ and given the nominal wage. Thus, they optimally forecast the technology and monetary shocks from their information set $\left(\bar{S}_{t}, w_{t}\right)$. Their labor choice satisfies:

$$
-\phi /\left(1-n_{t}\right)+w_{t} E\left\{\lambda_{t} \mid w_{t}, \bar{S}_{t}\right\}=0
$$

The household equates the marginal utility of leisure to the expected marginal utility of nominal wealth $\left(\lambda_{t}\right)$, scaled by the nominal wage. This expectational equation is solved using standard signal extraction methods. To conserve space, we omit the definition of equilibrium, and refer the reader to Cole, Ohanian, and Leung (2005).

\subsection{The Nonneutrality of Money and Imperfect Information}

We now show how the information imperfection generates the nonneutrality. These results are in the spirit of Lucas (1972), in that a standard signal extraction problem is used to infer the values of the shocks from a subset of prices. For heuristic purposes, we consider an i.i.d. money shock. The key equation is the household's labor-leisure first-order condition. 
Log-linearizing this condition yields:

$$
\hat{w}_{t}-\frac{\hat{n}_{t} N}{1-N}=-E\left\{\hat{\lambda}_{t} \mid \hat{w}_{t}, \bar{s}_{t}\right\}
$$

where capital letters are steady-state values, and the other variables are log-deviations from the steady state. With imperfect information, the household makes its labor supply decision by forecasting the marginal value of nominal wealth $\left(\hat{\lambda}_{t}\right)$, conditioning on the nominal wage $\left(\hat{w}_{t}\right)$ and the restricted state vector $\left(\bar{s}_{t}=\left(\hat{k}_{t}, \hat{z}_{t-1}, \hat{\tau}_{t-1}\right)\right)$. The log-linearized equation for $\hat{\lambda}_{t}$ is given by

$$
\hat{\lambda}_{t}=D_{\lambda k} \hat{k}_{t}+D_{\lambda z} \hat{z}_{t-1}+D_{\lambda \tau} \hat{\tau}_{t-1}+D_{\lambda \varepsilon^{z}} \varepsilon_{t}^{z}+D_{\lambda \varepsilon^{\tau}} \varepsilon_{t}^{\tau}
$$

where $D_{\lambda j}$ is the linearized coefficient for state variable $j$. Similarly, the log-linearized wage equation is given by

$$
\hat{w}_{t}=D_{w k} \hat{k}_{t}+D_{w z} \hat{z}_{t-1}+D_{w \tau} \hat{\tau}_{t-1}+D_{w \varepsilon} \varepsilon_{t}^{z}+D_{w \varepsilon^{\tau}} \varepsilon_{t}^{\tau}
$$

Given $\bar{s}_{t}$ and $\hat{w}_{t}$, the workers forecast

$$
\hat{\lambda}_{t}-E\left\{\hat{\lambda}_{t} \mid \bar{s}_{t}\right\}=D_{\lambda \varepsilon^{z}} \varepsilon_{t}^{z}+D_{\lambda \varepsilon^{\tau}} \varepsilon_{t}^{\tau}
$$

from observing

$$
\hat{w}_{t}-E\left\{\hat{w}_{t} \mid \bar{s}_{t}\right\}=D_{w \varepsilon^{z}} \varepsilon_{t}^{z}+D_{w \varepsilon^{\tau}} \varepsilon_{t}^{\tau} .
$$

The solution to this standard signal extraction problem is

$$
E\left\{\hat{\lambda}_{t} \mid \hat{w}_{t}, \bar{s}_{t}\right\}-E\left\{\hat{\lambda}_{t} \mid \bar{s}_{t}\right\}=\eta\left[\hat{w}_{t}-E\left\{\hat{w}_{t} \mid \bar{s}_{t}\right\}\right]
$$

where $\eta$ is the signal extraction parameter to be defined. Rewriting this equation yields

$$
E\left\{\left(D_{\lambda \varepsilon^{z}} \varepsilon_{t}^{z}+D_{\lambda \varepsilon^{\tau}} \varepsilon_{t}^{\tau}\right) \mid\left(D_{w \varepsilon^{z}} \varepsilon_{t}^{z}+D_{w \varepsilon^{\tau}} \varepsilon_{t}^{\tau}\right)\right\}=\eta\left(D_{w \varepsilon^{z}} \varepsilon_{t}^{z}+D_{w \varepsilon^{\tau}} \varepsilon_{t}^{\tau}\right)
$$

The optimal forecast of $\hat{\lambda}_{t}$ is given by

$$
E\left\{\hat{\lambda}_{t} \mid \hat{w}_{t}, \bar{s}_{t}\right\}=\left[D_{\lambda k}, D_{\lambda z}, D_{\lambda \tau}, \eta D_{w \varepsilon_{z}}, \eta D_{w \varepsilon_{\tau}}\right] * s_{t}
$$

where, the parameter $\eta$ is given by

$$
\eta=\frac{D_{\lambda \varepsilon^{z}} D_{w \varepsilon^{z}} \sigma_{\varepsilon_{z}}^{2}+D_{\lambda \varepsilon^{\tau}} D_{w \varepsilon^{\tau}} \sigma_{\varepsilon \tau}^{2}}{\left(D_{w \varepsilon^{z}}\right)^{2} \sigma_{\varepsilon z}^{2}+\left(D_{w \varepsilon^{\tau}}\right)^{2} \sigma_{\varepsilon \tau}^{2}} .
$$


The parameter $\eta$ depends on variances of the shock innovations and on linearization coefficients. This parameter lies between 0 (maximum nonneutrality) and -1 (minimum nonneutrality). It is 0 when the variance of money shocks is 0 . This is because with $\log$ utility, a productivity shock has no effect on the marginal value of nominal wealth, and thus $D_{\lambda \varepsilon^{z}}=0$. It is -1 when the variance of productivity shocks is 0 . This is because in this case money shocks raise the nominal wage one-for-one, ceteris parabus, and reduce the marginal value of nominal wealth one-for-one $\left(D_{w \varepsilon^{\tau}}=1\right.$, and $\left.D_{\lambda \varepsilon^{z}}=-1\right)$.

Consider a negative money shock that ultimately lowers the price level by 10 percent. This implies that the nominal wage must immediately fall to clear the labor market. If $\eta=-1\left(\sigma_{z}=0\right)$ then money is neutral, as the nominal wage also falls 10 percent, and this leads workers to raise their forecast of $\hat{\lambda}_{t}$ by 10 percent. Consequently, there is no change in any real variable. Next, consider the same shock, but the case in which is $\eta=0\left(\sigma_{\tau}=0\right)$ The nominal wage must fall to clear the labor market, but in this case the household infers that the lower nominal wage is entirely due to a negative real shock, rather than the negative monetary shock. This misperception of a lower real wage leads households to reduce their labor supply. Consequently, the equilibrium nominal wage falls less than the price level, and employment and output fall.

This model has a smaller nonneutrality than a predetermined wage model because the nominal wage in the misperceptions model partially responds to shocks to clear the labor market, with the size of that response governed by the nonneutrality parameter $\eta$. (The Appendix presents the sticky wage model). Specifically, the analogue of (2) in the predetermined wage model is given by:

$$
\hat{w}_{t}-\frac{\hat{n}_{t} N}{1-N}=-E\left\{\hat{\lambda}_{t} \mid \bar{s}_{t}\right\}
$$

In the predetermined wage model, the difference is that households forecast the marginal value of nominal wealth given only the restricted state vector, $\bar{s}_{t}$. This means that a contractionary money shock qualitatively works the exact same way in the two models.

\section{Quantitative Methodology}

In this section we describe the procedure we use to (1) identify the shocks, (2) assess the empirical plausibility of the shocks and the model findings, and (3) decompose output and price change into orthogonal components due to productivity and monetary shocks. We describe these procedures in some detail because to our knowledge they have not been used before in the DSGE literature and because they can be easily used in any log-linearized 
model. They may be particularly useful for others studying the Depression, given the data limitations in the 1930s,

\subsection{Identifying Productivity and Monetary Shocks}

Data limitations prevent us from using the standard approach to identifying productivity shocks, as TFP can be constructed for 5 of the 17 countries. Regarding money shocks, the identification of these shocks is complicated because money shocks are latent variables, and there is no canonical method for estimating monetary shocks during this period. We therefore develop a new procedure for identifying the two shocks. This procedure treats both the productivity and monetary shocks as latent variables, and solves for the values of the

shocks so that output and the price level in the model for each country and for each year matches the actual output and price data.

The procedure is simple to perform. Specifically, we take the linear equations for the log of the deflator and the log of output and solve for the values of the technology and monetary shocks that equate the model price and output variables to the actual data for these variables. Thus, we are solving two linear equations (the equations for price and output) in the two unknown values of the shocks. We match output and the price level because these are the two variables that are the focus of the Depression literature, and this is required to decompose the changes in these variables into monetary and productivity components. We will later compare the constructed productivity and monetary shocks to the actual productivity and money variables. This is described in the next subsection. Note that any study of the Depression requiring shock identification will need to address the complications associated with these data limitations

\subsection{Model Evaluation Procedures}

To evaluate the empirical plausibility of the shocks and the findings, we compare the shocks and a number of the endogenous variables from the model to actual variables.

\subsubsection{Evaluating the Shocks}

Regarding productivity, we compare productivity in the model to actual productivity for those countries for which it is available. TFP is available for 5 countries, and labor productivity from the industrial sector is available for 13 countries. Regarding the money stock, it is necessary to adjust for money demand shocks to make an informative comparison between the model money stock and the actual money stock, as the model does not include money 
demand shocks, but there is evidence of the shocks in the data. We did not add money demand shocks to the model because they are irrelevant for the purpose of decomposing output and price into productivity and monetary components, and thus would simply complicate the analysis. Regarding the irrelevance of money demand shocks, Cole and Ohanian (2001) showed that the impact of a money demand shock in this model is the same as that of a money supply shock, conditional on the equilibrium price change. In other words, what matters in this model is the change in the price level, not whether it is induced by money demand or money supply shocks. Since we are matching deflation exactly, this means that the decomposition results will be invariant to the inclusion of money demand shocks. The Appendix discusses this result.

We therefore compare model money to actual money by as follows. First, measure the money demand shock from the data using the standard money demand relation:

$$
\hat{m}_{d t} \equiv m_{t}-p_{t}-y_{t}-\alpha i_{t}
$$

where $m$ is the log of money stock, $y$ is the log of real GNP, $p$ is the log of the price level, $\alpha$ is the interest semi-elasticity, and $i$ is the nominal interest rate. If the model is generating empirically plausible movements in the money stock, then the implied money demand shock in the model, which is the difference between actual money and model money $\left(m_{t}-\hat{m}_{t}\right)$ should be very similar to the identified money demand shock from the data $\left(\hat{m}_{d t}\right)$. We will thus compare the difference between the model money stock and the actual money stock to the money demand shock from the data.

\subsubsection{Evaluating the Endogenous Variables}

Following the empirical evaluation of the two shocks, we will compare the time paths of several endogenous variables - consumption, labor, and the real wage - in the model to those in the data. To our knowledge, these comparisons of the time paths of different variables for a panel of countries have not been pursued in the broader DSGE business cycle literature.

\subsection{Decomposition Procedure}

To decompose output and prices into components from each shock, we first describe the stochastic process for the shock innovations. The productivity and monetary shocks are the 
sum of a common component and idiosyncratic components:

$$
\begin{aligned}
& \varepsilon_{z i t}=\mu_{i t}+u_{z i t}, \\
& \varepsilon_{\tau i t}=\gamma \mu_{i t}+u_{\tau i t} .
\end{aligned}
$$

where $\mu_{i t}$ is the common component of the productivity and monetary shocks in country $i$ in period $t$, and $u_{z i t}$ and $u_{\tau i t}$ are the idiosyncratic components of these two shocks. The common component is normalized to have a unit impact on the productivity shock, and the parameter $\gamma$ scales the impact of the common component on the monetary shock.

Both components are Gaussian and mean zero. The variance of the common components is $\sigma_{\mu}^{2}$ and the variances of the orthogonal components are $\sigma_{u_{z}}^{2}$ and $\sigma_{u_{\tau}}^{2}$, respectively. The common component $\mu$ allows for the possibility that the shocks may be correlated in population. $^{14}$

Constructing bounds on the maximum and minimum contributions of each shock for output and deflation is straightforward for mean zero shocks. However, we know a priori that the monetary and productivity shocks from the Depression will not be mean zero because we are analyzing a very unusual period of large output and price declines. We deal with this non-zero mean complication as follows. To construct the lower bound on the contribution of productivity for output, we first estimate $\mu_{i t}$ by projecting $\varepsilon_{z i t}-\bar{\varepsilon}_{z}$ on $\varepsilon_{\tau i t}-\bar{\varepsilon}_{\tau}$. Then we take the residuals from this projection, along with the mean, as our estimate of $u_{z i t}$, which we denote by $\hat{u}_{z i t}$, which consists of the mean of the productivity shock and the orthogonal mean-zero productivity shock component.

We then feed $\hat{u}_{z i t}$ into the model and construct output from this component alone, which we denote as $y_{z, i t}^{p}$. We then form the percentage of the sum of squared output deviations explained by $\hat{u}_{z i t}$ as:

$$
R_{y, z}^{2}=1-\frac{\sum_{i=1}^{17} \sum_{t=1930}^{1933}\left(y_{z, i t}^{p}-y_{i t}\right)^{2}}{\sum_{i=1}^{17} \sum_{t=1930}^{1933} y_{i t}^{2}},
$$

where $y_{i t}$ is the log-deviation of real output from its 1929 level in country $i$ in period $t$. We construct the lower bound on the contribution of productivity for price changes using an analogous procedure, which we denote as $R_{p, z}^{2}$. We use a symmetric procedure to construct the lower bound for the contribution of money shocks to output and price changes, $R_{y, \tau}^{2}$ and $R_{p, \tau}^{2}$.

Finally, we note two details about this conformity measure, one regarding the sum of

\footnotetext{
${ }^{14}$ This possible dependence may be due to institutional features, such as a productivity shock inducing an off-setting monetary change to maintain gold points. For our purposes, however we will not pursue a structural interpretation of this possible dependence.
} 
the contribution of the shocks, and the other regarding the contribution of any individual

shock. Regarding the sum of the shocks, if the shocks were mean zero, then $R_{y, z}^{2}+R_{y, \tau}^{2} \leq 1$, and equal to one only if the shocks were uncorrelated. However, with shocks that aren't mean zero, this inequality may not hold. We treat this complication as a sampling issue, and report the conformity measures as constructed. We stress that this complication will affect any analysis that decomposes the relative contributions of shocks for the Depression, or for that matter, any other period with non-mean zero shocks.

Regarding the contribution of an individual shock for a particular endogenous variable, it is possible that this could be negative. This generically arises in a multi-dimensional setting, as there are no restrictions on (5) to guarantee that the contribution of shock " $\varepsilon$ " for variable " $x$ ", $R_{x, \varepsilon}^{2}$, is positive. This will tend to occur when the impact of one shock in isolation changes an endogenous variable in the opposite direction than the variable actually moves. For example, negative productivity shocks in isolation will tend to generate inflation, rather than deflation, since lower output, ceteris parabus, induces higher prices. We will discuss both of these issues in greater detail when we present the decomposition results in Section 8.

\subsection{Parameter Values}

Table 4 presents the parameter values in which the length of a time period is one year. The discount rate is 0.95 , the exponent on labor in the production function is $2 / 3$, and the depreciation rate is 7 percent per year. We choose the preference parameters $\alpha$ and $\sigma$ such that the steady state of the model matches two long-run money demand observations: an interest semi-elasticity of money demand of -.08 and an average velocity level of 3.2 . We choose the leisure parameter $\phi$ so that households spend about $1 / 3$ of their time working in the deterministic steady state.

We choose the autocorrelation coefficient for the technology shock to be 0.8 , which is consistent with a quarterly value of 0.95 . We choose the autocorrelation coefficient for money growth to be zero, which is consistent with the average serial correlation of money growth during the gold standard period. We conducted a sensitivity analysis for this parameter between -0.5 and 0.5 and found that the results were insensitive to this variation.

As in Lucas (1972), the relative size of the innovation variances for the money supply and the technology shock determine the size of the impact of a money shock on output, and we label this nonneutrality parameter $\eta$. Our basic approach is to examine the results across the full range of nonneutrality values in the model, which extends from a purely neutral model $(\eta=-1)$, to the maximum nonneutrality, in which $\eta=0$. We will tend to focus on $\eta=-.5$ 
because it is the median value, and we also identify the value for $\eta$ that is implied by the variances of the productivity and monetary shocks that we calculate over 1930-33, which is $\eta=-0.9 .^{15}$ We will refer to $\eta=-0.9$ as the "fixed point" value for $\eta$.

Table 5 shows the impact of a contractionary money shock that reduces the price level by 10 percent for different values of $\eta$. The maximum nonneutrality decreases labor input by about 13 percent from a 10 percent decrease in the price level. The mid-range nonneutrality $(\eta=-.5)$ decreases labor input by about 9 percent in response to a 10 percent unexpected deflation. The fixed point value for $\eta(-0.9)$ depresses labor by about 2.6 percent in response to a 10 percent unexpected deflation. ${ }^{16}$

\section{Model Evaluation}

To evaluate the plausibility of the model and of the constructed shocks we make several comparisons between the model and the data at our benchmark parameterization. For comparisons between the same variable in the model and in the data, we construct the following statistic to summarize the conformity between the model and data:

$$
\operatorname{conformity}_{x}=\frac{\sum_{i, j}\left(x-x_{i j}^{d}\right)^{2}}{\sum_{i, j}\left(x_{i j}^{p}\right)^{2}},
$$

in which $x_{i, j}^{p}$ is the value of the variable " $x$ " from the model and $x_{i, j}^{d}$ is the value of variable " $x$ " from the data. This conformity statistic provides the percentage of squared change in the variable from 1929 that is explained by the model. It is identical to an $R^{2}$ measure without an intercept term. Table 6 summarizes the conformity measures for these variables for the benchmark parameterization, and for comparative purposes, it shows these measures for alternative values of the nonneutrality parameter. The comparative results are discussed at the end of this section.

In some cases, however, data limitations will prevent us from comparing the same object in the model to that in the data. For example, we compare industrial labor productivity from the data, which we have for most of our countries, to TFP from the model. In these cases, we do not expect the objects to move identically, but rather it is reasonable that they

\footnotetext{
${ }^{15}$ It is reasonable to wonder why we don't focus exclusively on $\eta=-0.9$. The main reason is that the 1930-33 period is obviously very unusual, and the derived shocks from this period may have different sample variances than those from the underlying p.d.f. In particular, the actual variance of the productivity shock was probably larger than was anticipated. This would argue for a higher value of $\eta$ than -0.9 .

${ }^{16}$ For comparative purposes, note that a model with our production technology, but in which wages are set in advance, drives down employment 30 percent from a 10 percent unanticipated deflation. This follows directly from equating the marginal product of labor to the real wage.
} 
would move similarly. For these cases we will calculate the correlations between the model and actual variables. To our knowledge, this type of procedure, which is designed to provide a comprehensive evaluation of model results, has not been used in the DSGE depression literature, nor has it been used in the broader business cycle literature.

The first evaluation is for TFP. We have TFP for Canada, France, Germany, the United Kingdom, and the United States for each year. The model explains $86 \%$ of the change in TFP for these countries between 1929 and 1933. Figure 2 plots this data, and shows a strong and systematic relationship between actual productivity and model productivity for each country and each year.

Our next evaluation makes a broader productivity comparison, but as noted above requires us to compare industrial labor productivity from the data to model productivity, which is for the entire economy. Given our strategy described above, we calculate the correlation between model TFP and actual industrial labor productivity. We have industrial labor productivity for 11 countries beginning in 1929 and 14 countries beginning in $1930 .{ }^{17}$

To provide a benchmark for comparing industrial labor productivity and TFP, we calculated the correlation between U.S. HP-filtered industrial labor productivity and U.S. HPfiltered aggregate TFP, which is 0.72 . This should be an upper bound on the correlation for the Depression period, as measurement error in the cross-section in the 1930s is likely larger than for the postwar U.S., and because of potential structural differences across countries. The correlation between model TFP and industrial labor productivity in the data for the set of 11 and 14 countries are 0.58 and 0.57 , respectively. We conclude from these comparisons that the productivity changes from the model are similar to those in the panel dataset during the Great Depression.

We next compare the model money stock the actual money stock. Recall we do not include money demand shocks in our model, since the decomposition results are invariant to including money demand shocks. But comparing the model money stock to the actual money stock requires adjusting for money demand shifts as described above. We therefore compare the implied money demand shock in the model to the money demand shock from the data, which is given by:

$$
\varepsilon_{i t}^{D}=m_{i t}-p_{i t}-y_{i t}+.08 i_{i t}
$$

where $m_{i t}$ is the actual change in the log of $\mathrm{M} 1$, and $i_{i t}$ is the change in the nominal interest

\footnotetext{
${ }^{17}$ All countries except for Czecholoslovakia, Denmark and Switzerland have industrial labor productivity beginning in 1930. Within this group of 11 countries, all expect for Austria, France, and Germany have industrial labor productivity beginning in 1929.
} 
rate relative to 1929. For the interest rate we use the government discount rate where available since it is probably the best measure of the opportunity cost of holding money that we have available, as it is a short-term rate and also is subject to relatively little default risk. For countries in which we do not have this rate, we used the interest rate that was the most reasonable proxy for the opportunity cost of holding money. ${ }^{18}$

Because there are several differences between the actual monetary measure and the monetary object in the model, we compare the model money demand shocks to those estimated from the data using correlations, rather than the conformity measure. These include the fact that countries have different levels of financial development, suggesting country-specific interest elasticities, that some countries had bank closings during the Depression, and the well-known differences between the actual measure of money from the data (M1), and the pure, non-interest bearing medium of exchange object in the model. Figure 3 shows that the money demand shocks from the data and the money demand errors in the model are systematically related. The correlation between the model and data is 0.76 .

We now turn to comparing the endogenous variables in the model to their data counterparts. We choose those variables that are central variables in the theory and which we have at least some data, which are labor, consumption, and wages. We find that the model accounts for 77 percent of the change in labor for the 7 countries for which we have aggregate employment (U.S., Canada, U.K, France, Germany, Australia and Japan). For example, the actual percentage change in U.S. labor between 1930-33 from 1929 is -6, -14 -25, and -20 percent, respectively (an average decline of 16.3 percent), while in the model it is $-8,-15-22$, and -20 (an average decline of 16.2 percent).

The model accounts for 69 percent of actual consumption change in the set of 8 countries for which we have consumption data (U.S., Canada, U.K, France, Germany, Australia, Sweden and Italy). It is worth noting that the model achieves a high coherence despite the anomalous behavior of consumption in Australia, which declines 2-3 times more than output declines. (In the other countries, consumption declines less than output). Omitting Australia from this calculation raises the fraction explained from 69 percent to 78 percent.

The coherence between model consumption and labor and actual consumption and labor indicates that the model is plausibly allocating supply change between the factors of production and productivity, and is plausibly allocating demand between consumption and the sum of investment (augmented with net exports, which is theoretically appropriate in a closed economy framework) and government spending, which tends to be fairly small in

\footnotetext{
${ }^{18}$ We have data on the discount rate for the following countries: Australia, Austria, Canada, Denmark, Finland, Germany, Italy, Japan, Netherland, Norway, Sweden, Switzerland, UK, US. For France we use a money market rate.
} 
many countries.

The consumption comparison is also informative because it provides a test of our assumptions regarding the persistence of the shocks in the model. Basic permanent income logic indicates that the magnitude of the fall in consumption, conditional on the fall in output, depends on the persistence of the shocks, as persistent shocks tend to generate a larger consumption change than temporary shocks. The average consumption decline in the data, which includes durable consumption, is 6 percent, compared to a 4 percent average decline in the model. Correcting for consumer durables, which is a form of investment, would reduce this 2 percent deviation between model and data. We make a rough correction for this by first noting that durables are about 3 times as volatile as consumption of non-durables and services, and assume that on average durables were about 15 percent of total consumption. This implies that the decline in actual consumption corrected for durables is about 5 percent, compared to the model decline of 4 percent. The implication is that the observed large consumption decline in the data requires a shock with a permanent component of roughly the size included in the model economy. ${ }^{19}$

We next compare model wages to industrial wages in the data. This comparison is significantly more complicated than for the other variables, however, because of a number of important measurement issues. These include (1) cyclical compositional changes among workers, (2) the wage rate in the model is for the aggregate economy, but the measured wage rate is just for the industrial sector, (3) the size and composition of the industrial sectors differs across countries, (4) wage survey methodologies differ across countries, and (5) data transcription errors may be large for some countries. ${ }^{20}$ We are able to make some adjustments for the first two of these problems but unfortunately not for the others. Thus, this wage comparison is probably less informative than the other comparisons. Regarding worker compositional change, the average quality of workers tends to rise during depressions because the least experienced and least productive employees are typically the first to be laid off. We have addressed this measurement problem by compositionally adjusting the wage rate in the model using the postwar U.S. estimates of cyclical labor composition bias produced by Solon, Barsky, and Parker (SBP, 1994). ${ }^{21}$

Table 7 examines the wages from the model. The table makes two comparisons. One

\footnotetext{
${ }^{19}$ Unfortunately we do not have sufficient information to correct each individual country's consumption for durables.

${ }^{20}$ Regarding this latter measurement issue, we found that the nominal wage index in some countries is implausibly constant (up to a decimal point) for a sequence of years, which will tend to lead to positive real wage measurement error during deflationary periods.

${ }^{21}$ The log-deviations in model real wages, $w$, were generated according to $\hat{w}=w-0.49 * n$, where $n$, the employment share, is serving as a proxy for unemployment. We compositionally adjust the model wages since we have measures of employment in the model for all of our countries.
} 
is between the model wage and the actual wage, and the other compares the output-wage relationship from the model to that in the data. For both comparisons, we focus on the compositionally adjusted model wage.

With the SBP compositional adjustment, the model real wage rises from its 1929 value in every year except in 1933, though the rise is not as much as in the data. The fact that the model wage is below the actual mean industrial wage is expected, as real industrial wages tended to rise more than the aggregate wage. For example, U.S. farm wages fell considerably in the depression. Adjusting for this fact implies that the gap between the model's economy-wide wage and actual wages is probably smaller than Table 7 suggests.

Regarding the correlation between the model and actual wage, we provide a benchmark for interpreting this correlation by reporting the correlation between the aggregate wage and the industrial wage during postwar U.S. business cycles. We measured the cyclical correlation between industrial wages and the aggregate wage using postwar U.S. HP-filtered data and obtained a value that ranges between of 0.48 and 0.8 , depending on the value of the smoothing parameter. ${ }^{22}$ Table 8 shows that the correlation between the model wage and the actual wage for each of the four Depression years ranges between 0.59 to 0.72 . This means that the correlation between the model wage and the industrial wage is comparable to that between industrial and economy-wide wages during postwar U.S. business cycles. A key implication of these wage comparisons is that the inclusion of negative productivity shocks in the model does not generate lower real wages, as might be expected. Rather, the combination of modestly non-neutral monetary shocks, with productivity shocks, generates real wages that are similar to actual wages.

Table 7 also compares the model wage-actual output correlation to the actual wageactual output correlation. This comparison is very informative, because it is well known that single shock models - either monetary or productivity - are inconsistent with outputwage correlations. Specifically, a monetary shock-sticky wage model generates a -1 correlation between output and real wages, and a productivity shock-RBC model generates a correlation near 1 . In sharp contrast, this model is consistent with the real wage-output correlation in 3 of the 4 depression years. The only significant deviation is in 1933, in which the actual wage-output correlation is below the model wage-output correlation. But the relatively low 1933 correlation is expected, as this is the year in which government labor policies in a number of countries began (e.g. the NIRA in the United States). The adoption of these policies will, almost by definition, lower the correlation between the real wage and output.

\footnotetext{
${ }^{22}$ The correlation is 0.48 for a smoothing parameter of 400 and is 0.84 for a smoothing parameter of 6.25. The U.S. annual series are average hourly earnings for manufacturing and average hourly earnings for the private economy, from 1955 to 2003.
} 
As discussed earlier, quantifying the impact of these policies in for this panel of countries is very interesting, but is beyond the scope of this paper.

The conformity of model productivity, money, consumption, labor, and wages to their data counterparts is very surprising, as there certainly was no presumption prior to the analysis that such a parsimonious, common-parameter model would perform this well. In particular, measurement error, the significant and large heterogeneity of output change across countries, and the differences in the stages of development across countries, clearly pose a significant challenge to such a simple and common parameter model.

Table 6 also shows these data-model comparisons for other values of the non-neutrality parameter, $\eta$. The main finding is that the comparison is not sensitive to values of this parameter in the moderate nonneutrality range $(-.25$ to -.75$)$, but the conformity of the model with the data declines for larger non-neutrality values or for a purely nonneutral model. To see this, note that the purely neutral model $(\eta=-1)$ accounts for only 46 percent of the change in labor, compared to 76 percent for the mid-range nonneutrality value, while the maximum nonneutrality $(\eta=0)$ accounts for 77 percent of TFP compared to 90 percent for a lower nonneutrality. It is natural to ask whether even larger nonneutrality values generate worse results. To assess the impact of a larger nonneutrality, we evaluated the conformity of the standard pre-determined wage model, which is briefly described in the Appendix. This model is similar to that in Chari, Kehoe, and McGrattan (2000), and Cole and Ohanian (2002). Model conformity deteriorates considerably in the pre-determined wage model, as it accounts for only about 26 percent of the change in labor. (For example, the pre-determined wage model generates a 39 percent decline in labor in the U.S. in 1932, compared to the actual 25 percent decline). Similarly, the fraction of TFP change that is accounted for by the pre-determined model is only 34 percent, compared to 86 percent for the benchmark value in the imperfect information model.

These findings show that accounting for the data requires a model with a low to moderate nonneutrality, and explain why the fixed point value of $(\eta=-0.9)$ is fairly close to neutral $(-1)$. Regarding this latter issue, note that monetary shocks in the model need to be fairly large (about as large as they are in the data) to account for the observed deflation in the panel. These large monetary shocks preclude a very large nonneutrality, as a large nonneutrality requires the variance of monetary shocks to be very low.

The main implication of the conformity between the model and the data suggests that it is reasonable to use the model for the next step in the analysis, which is to decompose output and price change into orthogonal components due to productivity (the "supply shock") and money (the "demand shock") in order to assess the relative importance of the two shocks for understanding output change and deflation. 


\section{The Relative Contributions of the Shocks}

Table 8 presents the contribution of technology and money shocks to the changes in output and prices for different values of the nonneutrality parameter $\eta$, along with the correlation between the two shocks. The first two rows of the table show the fraction of output and deflator change explained by the monetary shock alone, and by the productivity shock alone. The second two rows show the fraction explained by the uncorrelated component of the monetary shock alone, and by the uncorrelated component of the productivity shock alone. The main findings are that (i) productivity is about twice as important in accounting for output, (ii) money is by far the most important shock for explaining prices, and (iii) the productivity and money shocks are only weakly correlated.

As discussed above, the fact that both shocks have non-zero means generate lower bounds of the contribution for each shock that sum to more than one. Normalizing the lower bounds of the contribution of the productivity shock to sum to one, then the fourth row of the table shows that the lower bound for the contribution of the productivity shock to output ranges from 75 percent when the nonneutrality is low, to 51 percent at the maximum nonneutrality of money. At the benchmark nonneutrality of $\eta=-0.50$ the normalized lower bound for the contribution of productivity is $63 \%$. Thus, close to $2 / 3$ of the change in output is conservatively due to productivity. ${ }^{23}$ The table also shows that money shocks account for virtually all of the variation in prices. It is not surprising that the contribution of productivity shocks in isolation to prices is negative, as on average productivity generates lower output, which in turn raises prices.

These findings are consistent with the statistics presented in section 2, which indicated that accounting for deflation and output required two shocks, a shock with a large idiosyncratic component to account for output, and a shock with a large common component to account for deflation. Table 9 shows that the productivity and money shocks indeed have these features. The country-specific share of variation in the productivity shock exceeds 60 percent each year except 1932, and the country-specific share of variation in the money shock is less than 40 percent in every year except 1933. Thus, the simple reason why deflation/monetary shocks account for relatively little of output in the model is the same reason why deflation statistically accounts for relatively little output change in regression equation (1): output has a large country-specific component, and deflation is not very highly correlated with output.

\footnotetext{
${ }^{23} \mathrm{An}$ alternative to normalizing the output contributions of the two shocks to sum to 1 is to divide the fraction explained by productivity by the sum of the fractions explained by productivity and money. This also indicates that productivity accounts for about $2 / 3$ at the benchmark nonneutrality.
} 
Moreover, this model- based decomposition of output is entirely consistent with a statisticalbased decomposition of output. Specifically, we calculate output from our model with just the productivity shocks, and compare it to the residuals from the regression of output on deflation in regression equation (1). The regression residual and output from the model with just productivity are nearly identical; model output generated just from productivity accounts for 97 percent of the residual measure of output from the regression. This last finding highlights the earlier point that the first-order impact of deflation on output in the Depression in any log-linear model economy will necessarily be relatively small because output change is largely country-specific and deflation is not highly correlated with output change.

Finally, we test whether the decomposition results are sensitive to the assumption of a common nonneutrality parameter for all the countries. We relax this assumption by specifying the maximum nonneutrality value for the 5 countries with very large output declines (U.S., Canada, France, Germany, Austria), and the small nonneutrality value for the remaining countries with smaller output declines. Since deflation was on average about the same in both set of countries, this specification increases the potential explanatory power of monetary shocks for output by allowing these shocks to have a large effect on output in the large depression countries and a smaller effect in the other countries. The decomposition results did not change very much, with the relative contribution of productivity shocks for output falling about 6 percentage points from an average of about 72 percent to 66 percent.

The fact that productivity remains the most important factor for explaining output, even allowing for heterogeneity in the response of output to deflation, is not so surprising, as deflation was statistically insignificant in the regression that allowed for country-specific values for the deflation coefficient. Given the importance of productivity, the following section investigates the extent that productivity can be explained by various macroeconomic variables, with the goal of gaining an understanding of the productivity shocks.

\section{Understanding the Productivity Shocks}

The findings indicate (i) that output is primarily accounted for by productivity shocks, (ii) that deflation is accounted for by monetary shocks, and (iii) that productivity, money, consumption, labor, and wages in the model are similar to those in the data. The next step is to learn more about these productivity shocks. ${ }^{24}$

\footnotetext{
${ }^{24}$ It would also be interesting to gain a deeper understanding of the money demand shocks that we have identified, in a parallel fashion to our approach of analyzing productivity shocks. This would take us beyond the scope of the paper, however, and we therefore leave this for future research.
} 


\subsection{A Framework for Testing Hypotheses about Productivity}

This section develops a procedure for learning about these shocks that is based on the statistical relationship between productivity and other macroeconomic variables. This analysis is important, irrespective of whether these productivity shocks represent shifts in efficiency, or are the consequence of some other $\operatorname{shock}(\mathrm{s})$, as the growth model is the building block for DSGE macroeconomic analysis and because productivity shocks are required for the growth model to conform this well to the data. Thus, if we understand the productivity shocks whatever they are - then we can enhance our understanding of the Depression through either additional analysis with the growth model or augmenting the growth model with additional factors. But without this analysis of the productivity shocks, it is unclear which direction to take future DSGE investigations of the International Depression.

However, relatively little progress has been made in understanding the factors that may be contributing to productivity shocks during postwar business cycles or the Depression. ${ }^{25}$ Given that little is known, we frame the following analysis of productivity shocks around three different hypotheses. The first hypothesis is that the productivity shock is only the consequence of some other shock(s) in conjunction with either output/input mismeasurement (e.g. variable capacity utilization), or in conjunction with increasing returns. The implication of this first hypothesis is that if we account for variable factor utilization/IRS, and include shocks other than productivity shocks, then we can understand the Depression using the basic growth model. The second hypothesis is that the productivity shock represents change in the efficiency between inputs and output, and that if we understand that process, then we can understand the Depression as the consequence of productivity change using the basic growth model.

The third hypothesis exploits the fact that productivity shocks in a standard growth model are either observationally equivalent to, or are the consequence of, different shocks in more complex growth models. Specifically, some models with shocks to international trade or financial intermediation can be mapped into the standard growth model with productivity shocks. The implication of this hypothesis is that understanding the productivity shocks would indicate classes of richer growth models that are promising for future research. Chari, Kehoe, and McGrattan (2007) discuss these issues in detail.

Making progress on any of these hypotheses thus requires understanding the source of

\footnotetext{
${ }^{25}$ Ohanian (2001) suggests possible factors that contributed to productivity change during the Depression, but does not carry out any quantitative analysis of these factors. Regading postwar business cycles, Hansen and Prescott (1991) suggest productivity may be the consequence of changes in government policies and regulations, though we are unaware of any systematic tests of this hypothesis.
} 
these shocks. Our approach is to determine if the productivity shocks can be statistically explained by different macroeconomic variables. For example, if the productivity shock can be explained by financial intermediation variables, then models with intermediation shocks would be a promising avenue for further research. We proceed by fitting a regression of the productivity innovation from the model on different macro variables: $\varepsilon_{z i t}=X_{i t} \beta$, where $\varepsilon_{z i t}$ is the productivity innovation, $X_{i t}$ is a vector of macroeconomic variables and $\beta$ is a vector of coefficients.

To our knowledge, this is the first analysis of this type in the DSGE-depression literature. The covariates we investigate are chosen on the basis of theoretical interest and data availability. There are financial variables (a nominal interest rate, an ex-post real interest rate, the Bernanke-James (1990) measure of banking panics, and the real value of the stock market), four monetary variables (deflation, M0, M1, M1-M0, which represents the endogenous component of M1)), and one international trade variable (the real exchange rate). All of these variables are described in detail in the Appendix. We first estimate regressions with one variable at a time to maximize the potential explanatory value of each of these variables. The regressions take the following form, where $x$ represents the single explanatory factor:

$$
\varepsilon_{z i t}=\gamma x_{i t}+u_{i t}
$$

\subsection{Accounting for Productivity with Macroeconomic Variables}

Table 10 shows the goodness of fit statistic for these regressions, which is the same conformity measure we have used previously. Our main finding is that real stock prices are the only variable that is substantially related to the productivity innovation, accounting for 40 percent of its sum of squared deviations. Moreover, the correlation between the productivity innovation and real stock price is 0.70 .

Most of the other variables account for little of the productivity innovation. Deflation explains just 1 percent. The monetary base, which is the monetary aggregate most closely controlled by central banks, explains none of the productivity shock. M1 explains 23 percent, but this is driven by the endogenous component of M1 (M1-M0) and the covariance between the base and the endogenous component of M1. Nominal interest rates and real interest rates are both unimportant, as is the real exchange rate. The Bernanke-James banking panic variable explains 19 percent.

These results cast doubt on the plausibility of some hypothesis 1 explanations, including deflation-based and exchange-rate based explanations of productivity through input mismeasurement such as capacity utilization, labor hoarding, or increasing returns. 
For comparative purposes, the table also presents the conformity measure for each of these variables (except the banking variable, which is unavailable for this period) in the same regression estimated using annual U.S. post-World War II data. The most striking comparison is with the stock market. The explanatory power is only 5 percent in postwar U.S. data, compared to 40 percent during the depression.

We also evaluated whether the non-stock market variables were jointly important for explaining the Depression productivity shocks. Specifically, we tested whether deflation, M1, the nominal interest rate and the banking panic variable add any significant explanatory power beyond the stock price variable. They do not - the $F$ statistic for the joint significance of these variables is 1.43 , compared to the 5 percent critical value of 2.09. We also evaluated the joint explanatory power of these other variables without the stock market in the regression. The explanatory power from the regression from these four variables is considerably less than that from just the stock market.

We also estimated a fixed-effects regression and the stock market variable to test whether the stock market is explaining any variation in productivity over time, as the fixed-effects regression controls for country-specific factors. We find that this is indeed the case; the stock market variable is significant at the 1 percent level (t-statistic $=2.66)$, which indicates that the stock market is not just standing in for average cross-country differences in productivity change, but rather it can statistically account for changes in productivity over time within a country. This finding provides further evidence of a significant relationship between the stock market and productivity change, and suggests that the most promising channel for understanding TFP is through a mechanism that is associated with the stock market.

We next test whether there is a significant relationship between lagged real stock prices and the productivity innovations. This provides a test of whether the productivity shock was forecastable, and whether stock prices were possibly reacting to anticipated low economic activity. This is important because the standard view is that the Depression was due to a long sequence of transitory and unforcastable shocks (e.g. the Robert Lucas interview in Klamer (1981)), but this view stands in contrast to the predictable and persistent productivity shocks in the model economy. This lagged analysis also evaluates whether there is a significant relationship between the stock market and productivity after removing the contemporaneous endogenous component from stock prices.

We therefore regressed the productivity innovations on lagged real stock prices, and found that the lagged stock market accounts for 32 percent of the productivity innovations. It is also interesting to note that lagged real stock prices account for 50 percent of the productivity shock level (as opposed to the innovation) during the Depression, compared to just one percent in postwar U.S. data. These findings show that there is a systematic and 
quantitatively important relationship between the stock market and productivity, and that there is a significant predictable component of productivity during the Depression.

\subsection{Understanding the Change in the Stock-Productivity Rela- tionship}

The very large difference between the postwar stock-productivity statistical relationship, and that during the Depression, raises the very interesting question of the source of that difference. This subsection evaluates this question, and establishes that virtually all of the difference can be accounted for by a change in the size of the productivity shocks within a common linear statistical model that applies to both periods.

First, we write the log of the deviation in the stock price due to a productivity deviation $(z)$, and other factors $(n)$, as:

$$
s=\gamma z+n=\gamma\left(\rho z_{-1}+\varepsilon_{z}\right)+n .
$$

We now show that the very large change in the stock market-productivity relationship during the Depression is exactly expected, given the change in the size of the productivity shocks. To see this, we first establish the relative sizes of the variances of the productivity shock, the stock market, and the other factors for the postwar period.

First, normalize the variables by $\gamma$, and recall that the $R^{2}$ in the postwar period is about .05 , and is given by:

$$
R^{2}=\frac{\sigma_{\varepsilon_{z}}^{2}}{\sigma_{s}^{2}}=.05
$$

Assuming that $n$ and $z$ are orthogonal, and given the fact that $\sigma_{z}^{2}$ is 2.8 times as large as $\sigma_{\varepsilon_{z}}^{2}$ (recall that $\rho=0.8$ ), we can also express the $R^{2}$ as:

$$
R^{2}=\frac{\sigma_{\varepsilon_{z}}^{2}}{\sigma_{n}^{2}+\sigma_{s}^{2}}
$$

which implies the following relationship between the variance of productivity and the variance of the other factors $(n)$ :

$$
\sigma_{n}^{2}=\left\{\frac{1}{.05}-2.8\right\} \sigma_{\varepsilon_{z}}^{2}=17.2 \sigma_{\varepsilon_{z}}^{2} .
$$

In the depression, the standard deviation of the productivity innovation rises from 0.006 to 0.037, which implies a 38-fold increase in its variance. Assuming $\sigma_{n}^{2}$ remains in proportion to $\sigma_{\varepsilon_{z}}^{2}$, then it follows that the $R^{2}$ calculated from a regression of productivity innovations on the stock market over the $1930-33$ period would average about 0.48 , which is close to the 
actual $R^{2}$ of 0.40 that we observe. Thus, the large increase in the productivity-stock market statistical relationship during the Depression is exactly what is expected, given our finding of a large increase in the size of the productivity shock during the Depression.

\subsection{The Contribution of the Stock Market Component of TFP to the Depression}

Our approach to interpreting the productivity shock and the Depression as causally related to the stock market has a well-established microeconomic counterpart in the corporate finance literature. In particular, this literature has compiled considerable microeconomic evidence on the impact of "financial distress", which the literature broadly defines as a firm having difficulty meeting scheduled debt payments, on stock prices and firm performance, including profits and productivity. The findings from this literature, some of which are summarized in the Appendix, indicate a significant negative effect of financial distress on stock valuation and firm profits and productivity. These findings have motivated the theoretical finance literature to develop several models that formally link between financial distress and firm performance, which are also summarized in the Appendix.

This discussion suggests that a theoretical model with a specific linkage from the stock market/financial shocks to productivity could be constructed to analyze the Depression. How much of the Depression could such a model account for? To assess the quantitative potential of such a model, we conduct a simple analysis with our existing model. The analysis decomposes productivity into two exogenous components, a stock-related component, and a residual component as follows:

$$
\begin{aligned}
& \varepsilon_{z t}=\phi s_{t}+\mu_{t} \\
& \bar{\varepsilon}_{z t}=\phi s_{t},
\end{aligned}
$$

where $\varepsilon_{z t}$ is our measured TFP innovation, $s_{t}$ is the log-deviation in the real stock price from 1929, and $\mu_{t}$ is the component of the productivity innovation that is orthogonal to the stockmarket. We estimate $\phi$ using OLS over the 1930-33 period from the productivity innovations and the data on stockmarket indices for the 15 countries for which we have the stockmarket data. ${ }^{26}$ We then feed $\bar{\varepsilon}_{z t}$ and our original measure of $\varepsilon_{\tau t}$ into the model and measure the fraction of output and price changes that the model accounts for using the conformity measure (5).

The results are promising; the model accounts for 71 percent of squared output change

\footnotetext{
${ }^{26}$ We have data on a stockmarket index for all of our countries except Finland and Italy.
} 
and 93 percent of the squared change in the deflator in the panel between 1929-33. This indicates that modeling the connection between the stockmarket and TFP in a more complex growth model is a promising approach to gaining a deeper understanding of the Great Depression.

\section{A Comparison with the Literature}

We now compare our findings with other DSGE analyses of the Great Depression. This is somewhat limited because most of the countries we analyze here have not been previously studied in the DSGE framework, and because existing analyses tend to focus on a single shock and also do not conduct the analyses we pursue in terms of comparing the model's predictions for money, productivity, consumption, labor, and wages, and our analysis of prices. With this in mind, we note that our finding that productivity shocks are an important factor for output is consistent with Cole and Ohanian's (1999) and Chari, Kehoe, and McGrattan's (2006) DSGE analyses of the U.S., with Amaral and McGee's (2002) analysis of Canada, with Fisher and Hornstein's (2002) analysis of Germany, and Perri and Quadrini's (2002) analysis of Italy.

Our finding that money shocks, operating through imperfectly flexible wages, also played some role in accounting for output, is consistent with Fisher and Hornstein for Germany, with Perri and Quadrini for Italy, with Christiano, Massimo, and Motto (2003) for the U.S., and qualitatively with the very interesting work of Bordo, Erceg, and Evans (2000) (hereafter BEE) for the U.S. ${ }^{27}$ Quantitatively, however, our findings indicate that the deflation/wage channel played a substantially smaller role in accounting for output than BEE conclude. This is because BEE study the U.S. Depression with only deflationary money shocks operating through pre-determined wages. BEE's analysis is inconsistent with CKM's demonstration that shows accounting for the U.S. Depression in a standard growth model requires both a labor wedge and a productivity wedge. Consequently, the BEE model, or any standard growth model with just the deflation/sticky wage channel, will generate a counterfactually large decline in labor and a counterfactully large increase in labor productivity during the Depression. For example, the pre-determined wage model considered here, which is similar to BEE, generates a 39 percent U.S. labor decline in 1932, which represents a more than 50 percent error relative to the actual decline of 25 percent. In addition, model labor

\footnotetext{
${ }^{27}$ Christiano, Massimo, and Motto use an interesting model that is very different from any of the other papers in the literature, and this complicates a making comparison with our work. However, our finding that a financial factor may be central may be related to their findings about the U.S., which also stress the role of financial markets.
} 
productivity rises 10 percent, compared to the actual 5 percent decline in the data for 1932.

It would be possible to introduce a productivity wedge in the BEE model. This could be easily done with productivity shocks, which would tend to bring their model results close to those reported here. Recall, however, that the alternative approach of introducing a productivity wedge through deflation-induced capacity utilization in a model with just the deflation/sticky wage channel is inconsistent with the panel data as (i) productivity shocks are empirically orthogonal to deflation, (ii) real wages are positively correlated with output, and (iii) deflation explains relatively little of output change.

We are unable to compare our findings regarding the contribution of productivity and money for the change in the deflator, regarding the consistency of model versus data for consumption, labor, money, and wages, and regarding the correlation between productivity shocks and other variables, such as the stock market, as the other studies in the literature have not conducted these extended evaluations. It is interesting to note, however, that the deviations between the model variables and the data in our Depression model are at least comparable, and in some cases smaller, than model-data deviations measured in equilibrium path analyses from the postwar period (see the summary of these studies in McGrattan and Ohanian, 2007).

\section{Summary and Conclusion}

This paper is the first DSGE analysis of the International Depression, with the explicit focus of bringing cross-country evidence to bear on this event. This analysis is a natural first step in this process, given the increasing use of DSGE modeling of single-country Depression analyses and given the long-standing interest in exploiting cross-country evidence. The contributions of this paper are as follows:

(1) We show that accounting for both deflation and output in the international cross section cannot be accomplished with a single shock, but rather requires a multi-factor approach. Specifically, any model must confront the fact that there is enormous real output heterogeneity across countries, despite deflation homogeneity across countries. The principal shock(s) driving output thus must have a large country-specific component, while the principal shock(s) driving deflation must have a large common component.

(2) We develop a stochastic growth model, that includes a monetary misperceptions mechanism in the spirit of Lucas (1972). Requiring the model to exactly match output and deflation generates changes in productivity, money, consumption, and labor in the model 
that account for about 70-90 percent of the actual changes in these variables, and generates wage movements that are very similar to those in the data, and generate a wage-output correlation that is very similar to that in the data. The productivity shock has a large country specific component and the monetary shock has a large common component.

(3) We find that accounting for the Depression in a growth model requires large productivity shocks; about $2 / 3$ of the Depression is conservatively accounted for by productivity, and about $1 / 3$ by monetary shocks. The fact that deflation and output are largely orthogonal in the panel means that deflation will have a very limited explanatory role in any log-linear model.

(4) We correlated the productivity shocks with several macro variables to gain an understanding of productivity. Stock prices are by far the most important predictor of the productivity shocks, with a correlation of about 0.7. Other explanations, including capacity utilization operating through deflation, interest rates, exchange rates, or base money, are uncorrelated with productivity. Presuming that the causality runs from changes in asset values to TFP, we find that the stock-market related component of productivity and the money shocks account for 71 percent of output changes and 93 percent of price change in the panel.

(5) Our statistical and model-based findings have implications for studies that have focused on the gold standard. One implication is that our analysis strongly indicates that the international deflation was the result of the international monetary contraction, with monetary shocks accounting for virtually all of the deflation in the model. This provides model-based evidence that complements the empirical and narrative analyses that argue deflation was indeed the consequence of monetary shocks associated with the international gold standard (see Eichengreen (1991)). In contrast, both our statistical and model-based findings indicate that monetary-deflation forces played a smaller role in the output decline of the international Depression than has been suggested by the gold standard literature.

The conformity of this parsimonious model with the data is very surprising because of the common specification across countries, because of the different stage of development across countries and other country-specific factors, because of measurement error, and because we have excluded several other factors from the model that are cited in the International Depression literature. The conformity of this model with the data thus indicates that if other factors are quantitatively important, then within the context of the growth model that importance primarily operates through the productivity channel of the model.

Accounting for the International Depression in the growth model requires large productivity shocks that are largely orthogonal to deflation, monetary factors, and interest rates and exchanges rates. Thus, understanding the depression requires understanding these productivity shocks. The fact that the stock market is the only variable closely related to 
productivity means that the most promising avenue for understanding these productivity shocks, and gaining a deeper understanding of the international depression, is through a model that theoretically connects productivity to financial market imperfections. Developing and tailoring such a model for the International Depression is important future work.

\section{References}

[1] Andrade Gregor and Steven Kaplan. 1998. How Costly is Financial (Not Economic) Distress? Evidence from Highly Leveraged Transactions That Became Distressed. Journal of Finance 53(5) (October): 1443-1493.

[2] Amaral, Pedro S. and James C. MacGee. 2002. The Great Depression in Canada and the United States: A Neoclassical Perspective, Review of Economic Dynamics, 5 (January): 45-72.

[3] Backus, David, Patrick Kehoe and Finn Kydland. 1992. International Real Business Cycles. Journal of Political Economy, 100 (4) 745-775.

[4] Backus, David K. \& Crucini, Mario J., 2000. Oil prices and the terms of trade, Journal of International Economics, Elsevier, vol. 50(1), pages 185-213.

[5] Bernanke, Ben S. 1983. Nonmonetary Effects of the Financial Crisis in Propagation of the Great Depression. American Economic Review 73 (June): 257-76. . 1995. The Macroeconomics of the Great Depression: A Comparative Approach. Journal of Money, Credit, and Banking 27 (February): 1-28.

. 2004. Interview by Art Rolnick, The Region 18 (June): 19-27, Federal Reserve Bank of Minneapolis.

[6] Bernanke, Ben S., and Kevin Carey. 1996. Nominal Wage Stickiness and Aggregate Supply in the Great Depression. Quarterly Journal of Economics 111 (August): 853-83.

[7] Bernanke, Ben S. and Harold James. 1990. The Gold Standard, Deflation, and Financial Crisis in the Great Depression: an International Comparison. Working Paper 3488, National Bureau of Economic Research.

[8] Bernanke, Ben S. and Martin L. Parkinson. 1991. Procyclical Labor Productivity and Competing Theories of the Business Cycle: Some Evidence from Interwar U.S. Manufacturing Industries, Journal of Political Economy 99 (June): 439-59.

[9] Beaudry, Paul, and Frank Portier. 2002. The French Depression in the 1930s. Review of Economic Dynamics 5 (January): 73-99. 
[10] Bordo, Michael D., Christopher J. Erceg and Charles L. Evans. 2000. Money, Sticky Wages, and the Great Depression. American Economic Review 90 (December): $1447-63$.

[11] Chari, V. V., Patrick J. Kehoe, and Ellen McGrattan. 2001. Accounting for the Great Depression. American Economic Review 92 (May): 22-27.

[12] Chari, V. V., Patrick J. Kehoe, and Ellen McGrattan. 2004. Business Cycle Accounting. Working Paper 625, Federal Reserve Bank of Minneapolis.

[13] Choudhri, Ehsan U., and Levis A. Kochin. 1980. The Exchange Rate and the International Transmission of Business Cycle Disturbances: Some Evidence from the Great Depression. Journal of Money, Credit, and Banking 12 (November, Part 1): 565-74.

[14] Christiano, Lawrence J., Roberto Motto, and Massimo Rostagno. 2004. The Great Depression and the Friedman-Schwartz Hypothesis. Working Paper 0318, Federal Reserve Bank of Cleveland. Forthcoming, Journal of Money, Credit and Banking.

[15] Christiano, Lawrence J., Martin Eichenbaum, and Charles Evans. 2001. Nominal Rigidites and the Dynamic Effects of a Shock to Monetary Policy. Working Paper 8403, National Bureau of Economic Research. Forthcoming Journal of Political Economy.

[16] Cole, Harold L. and Lee E. Ohanian. 1999. The Great Depression in the United States from a Neoclassical Perspective. Federal Reserve Bank of Minneapolis Quarterly Review (Winter): 2-24.

. 2000. Re-examining the Contributions of Money and Banking Shocks to the U.S. Great Depression. Staff Report 270, Federal Reserve Bank of Minneapolis. . 2001. Re-examining the Contributions of Money and Banking Shocks to the U.S. Great Depression. In NBER Macroeconomics Annual 2000, Ben Bernanke and Ken Rogoff, eds. Cambridge, Mass.: MIT Press, pp.183-227.

. 2002. The Great U.K. Depression: A Puzzle and Possible Resolution. Review of Economic Dynamics 5 (January): 19-44.

. 2004. New Deal Policies and the Persistence of the Great Depression, Journal of Political Economy, 112(4), 779-816.

[17] Cole, Harold L., Lee E. Ohanian and Ron Leung. 2005. Deflation and the International Great Depression: A Productivity Puzzle, NBER working paper \#11237.

[18] Crucini, Mario J., and James Kahn. 1996. Tariffs and Aggregate Economic Activity: Lessons from the Great Depression. Journal of Monetary Economics 38 (December): 427-67. 
[19] Eichengreen, Barry. 1992. Golden Fetters: The Gold Standard and the Great Depression, 1919-1939. NBER Series on Long-Term Factors in Economic Development. Oxford: Oxford University Press.

[20] Eichengreen, Barry, and Jeffrey Sachs. 1985. Exchange Rates and Economic Recovery in the 1930s. Journal of Economic History 45 (December): 925-946.

[21] Field, Alexander J. 1984. A New Interpretation of the Onset of the Great Depression. Journal of Economic History 44 (June): 489-498.

[22] Fisher, Jonas D. M., and Andreas Hornstein. 2002. The Role of Real Wages, Productivity, and Fiscal Policy in Germany's Great Depression: 1928-1937, Review of Economic Dynamics 5 (January): 100-127.

[23] Friedman, Milton, and Anna J. Schwartz. 1963. A Monetary History of the United States, 1867-1960. Princeton, NJ: Princeton University Press for NBER.

[24] Gandolfi, Arthur. 1974. Stability of the Demand for Money during the Great Contraction. Journal of Political Economy, vol. 82, no. 5, pp. 969-983.

[25] Harrison, Sharon, and Mark Weder. 2004. Did Sunspot Forces Cause the Great Depression? Discussion paper, Barnard College, NY, NY.

[26] Kendrick, John W. 1961. Productivity trends in the United States. Princeton, NJ: Princeton University Press.

[27] Klamer, Arjo. 1983. Conversations with Economists Totowa, N.J. Rowman and Allenheld.

[28] Kydland, Finn E., and Edward C. Prescott. 1982. Time to Build and Aggregate Fluctuations. Econometrica 50 (November): 134-70.

[29] Lucas, Robert E., Jr. 1972. Expectations and the Neutrality of Money. Journal of Economic Theory 4 (April): 103-24.

[30] Maksimovic, Vohislav and Gordon Phillips. 1998. Asset Efficiency and Reallocation Decisions of Bankrupt Firms. Journal of Finance 53(5) (October): 1495-1532.

[31] McGrattan, Ellen R., and Lee E. Ohanian, 2007, "Does Neoclassical Theory Account for the Effects of Big Fiscal Shocks? Evidence From World War II", NBER Working Paper 12130.

[32] Ohanian, Lee E. 2001. Why Did Productivity Fall So Much during the Great Depression? American Economic Review 91 (May): 34-38. 
[33] Ohanian, Lee E. 2004. Liquidity Shocks and the Great Depression, forthcoming, Journal of Money, Credit, and Banking.

[34] Opler Tim and Sheridan Titman. 1994. Financial Distress and Corporate Performance, Journal of Finance 49(3) (July): 1015-1040.

[35] Perri, Fabrizio, and Vincenzo Quadrini. 2002. The Great Depression in Italy: Trade Restrictios and Real Wage Rigidities. Review of Economic Dynamics 5 (January): $128-151$.

[36] Solon, Gary, Robert Barsky, and Jonathan A. Parker. 1994. Measuring the Cyclicality of Real Wages: How Important Is Composition Bias? Quarterly Journal of Economics 109 (February): 1-25.

[37] Temin, Peter. 1989. Lessons from the Great Depression. Cambridge, Mass.: MIT Press. . 1993. Transmission of the Great Depression. Journal of Economic Perspectives 7 (Spring): 87-102.

\section{Appendix}

\subsection{Data}

The primary data source of the data is B.R. Mitchell's International Historical Statistics. This includes most of the data on real and nominal GDP, industrial wages, production and prices, as well as the agricultural and industrial shares of GDP. Data on the stock market and gold parities come from the League of Nations Statistical Yearbooks from 1933 to 1940. Where available, we have used the latest official publications of historical data. This includes the data for Australia, Canada, Japan, the United Kingdom, and the United States. We

have also endeavored to use the latest revisions of data where available. This includes the data for France, Germany, Italy, and Sweden. Listed bellow are the data sources by country. Unless otherwise indicated, the data used are from B.R. Mitchell and the League of Nations.

\section{Australia}

Nominal and real GDP, GDP deflator: Butlin, M.W., 1977, A Preliminary Annual Database 1900/01 to 1973/74, Research Discussion Paper 7701, Reserve Bank of Australia.

Industrial production, price and wage indices: Australian Historical Statistics (Wray Vamplew, ed.), New York: Cambridge University Press, 1987.

\section{Canada}


Nominal and real GDP, GDP deflator, industrial production and wages: Statistics Canada, Historical Statistics (SC-HS).

(http://www.statcan.ca/english/freepub/11-516-XIE/sectiona/toc.htm)

\section{France}

Nominal and real GDP, GDP deflator, industrial production: Beaudry, P., and Portier, F., 2002, The French Depression in the 1930s. Review of Economic Dynamics 5 (January): 73-99

Note that the data provided by Beaudry and Portier were derived from data in Villa, P., 1993, Une Analyse macro-Economique de la France au XXieme Siecle. Paris: Presses du CNRS.

\section{Germany}

Nominal and real GDP, GDP deflator, industrial wages: Fisher, J., and Hornstein, A., 2002, The Role of Real Wages, Productivity, and Fiscal Policy in Germany's Great Depression, 1928-1937, Review of Economic Dynamics 5 (January): 100-127

\section{Italy}

Nominal and real GDP, GDP deflator, industrial wages, production, and prices: Perri, F., and Quadrini, V., 2002, The Great Depression in Italy: Trade Restrictions and Real Wage Rigidities, Review of Economic Dynamics 5 (January) 128-151.

Note that the data provided by Perri and Quadrini were based on data in (i) Ercolani, P., 1978, Documentazione Statistica di Base in (G. Fua), Lo sviluppo Economico in Italia, 3 : 388-472, and (ii) Rey, G., 1991, I Conti Economici dell'Italia, Bari: Laterza.

\section{Japan}

Industrial prices and wages: (i) Hundred-Year Statistics (100 Years) of the Japanese Economy, 1966, Statistis Department, Bank of Japan, and (ii) Supplement to Hundred-Year Statistics of the Japanese Economy (English translation of footnotes).

\section{Sweden}

Real GDP, GDP deflator, industrial production, prices, and wages: John Hassler's data set at (http://hassler-j.iies.su.se/SWEDATA/).

Note that the data used from Hassler's data set were derived from Krantz, O., and Nilsson, C-A., 1975, Swedish National Product, 1861-1970, Lund. 


\section{United Kingdom}

Nominal and real GDP, GDP deflator, industrial production, prices, and wages: Feinstein, C.H., 1972, National Income, Expenditure and Output of the United Kingdom, 1855-1965, Cambridge University Press.

\section{United States}

Nominal and real GDP, GDP deflator for 1919-29: Romer, C., 1989, The Prewar Business Cycle Reconsidered: New Estimates of Gross National Product, 1869-1908.

Nominal and real GDP, GDP deflator for 1929-40: Bureau of Economic Analysis, National Income and Product Accounts, Table 1.2B and Fixed Asset Tables, Table 1.2.

Industrial production: Board of Governors of the Federal Reserve Bank, series FRB B50001.

Industrial prices: Historical Statistics of the United States: Colonial Times to 1970, part 1, (HSUS), U.S. Bureau of the Census.

Industrial wages: Hanes, C., 1996, Changes in the Cyclical Behavior of Real Wage Rates, 1870-1990, Journal of Economic History.

\subsection{Choice of Price Index}

We use the GNP deflator as a price index in our modelling and in our calculations because it is a measure of final goods prices. The empirical literature, which focuses on sticky wage models, including (Eichengreen and Sachs (1985), Bernanke and Carey (1996)) use the WPI, which is inappropriate because this index is not the price of final output, which is required for the sticky wage model, but rather the WPI is a bundle of input prices. Tables A3 and A4 report the composition of the wholesale price index and the industrial production index for a number of countries. Two things stand out. First, the wholesale price index is largely based on a bundle of raw input prices, and second, the correspondence between the composition of the wholesale price index and the industrial production index is very poor. For example, in Czechoslovakia the WPI puts a weight of $78 \%$ on agricultural, mining and energy products, while the industrial production index puts a weight of $73 \%$ on manufacturing products. In France the WPI puts a weight of $44 \%$ on food and agricultural products while the industrial production index puts a weight of $0 \%$ on these same products. 


\subsection{Irrelevance of Money Demand Shocks}

Conditional on the price change, the impact of a money supply or money demand shock on output, labor and the wage rate is the same. To see this, consider the follow three loglinearized equations, where lower case variables denote log-deviations from the steady state. The first equation is the optimal labor condition of the household, the second is the optimal employment condition of the firm, and the third is the production function.

$$
\begin{gathered}
w(t)-(n(t) * N /(1-N))=-E\{\lambda(t) \mid w((t), \bar{s}(t)\} \\
p(t)+z(t)+\gamma(k(t)-n(t)=w(t) \\
y(t)=z(t)+\gamma k(t)+(1-\gamma) n(t)
\end{gathered}
$$

The first equation implicitly determines the labor supply schedule given the wage and the second determines the labor demand schedule. Note first that the labor demand schedule depends only on the change in the price, and not whether the change came from a money supply or money demand shock. Similar, $E\{\lambda(t) \mid w(t), \bar{s}(t)\}$ doesn't depend upon the source of the observed wage change. Hence, these two schedules are the same irrespective of whether the price change came from a money demand or supply shock and they therefore yield the same equilibrium levels of the wage, employment, and output.

\subsection{Pre-Determined Wage Model}

The environment of the pre-determined wage model differs only in that aggregate labor is a CES function of individual labor. This is included so that individual workers are able to set their wage. The labor aggregate is given by:

$$
L=\left[\int_{0}^{1} L(i)^{\theta} d i\right]^{1 / \theta}
$$

The system of equations characterizing the equilibrium of the pre-determined wage model is the same as the misperceptions model with the exception of the equation relating the wage, the disutility of effort, and the marginal utility of wealth. This condition in the pre-determined wage model is given by

$$
E\left\{\left[\left(\frac{1}{W_{t}} \frac{B}{1-N_{t}}\right)-\theta \lambda_{t}\right] N_{t} \mid K_{t}, z_{t-1}, \tau_{t-1}\right\}=0
$$


instead of

$$
-B /\left(1-N_{t}\right)+W_{t} E\left\{\lambda_{t} \mid W_{t}, K_{t}, z_{t-1}, \tau_{t-1}\right\}=0 .
$$

When we log-linearize, this difference effects the aggregate steady state values around which we linearize, and the conditioning in the expectation of $\log$ deviation in $\lambda$, which is the marginal value of nominal wealth. Otherwise, the equations in the two models are identical.

\subsection{Financial Distress, Stock Valuation, and Firm Performance: Theory and Evidence}

The corporate finance literature has evaluated both the direct and the indirect costs of financial distress, which is generally taken to mean difficulty meeting scheduled fix payments. The direct costs include the administrative costs and legal fees associated with bankruptcy, which have been estimated to be around $4 \%$ of market value. ${ }^{28}$ The indirect costs include misplaced managerial effort, costly reductions in capital and sales of assets at depressed prices. While not all of these costs will translate into falls in measure TFP, some of them, such as misplaced managerial effort and the potential misallocation of capital can.

Andrade and Kaplan (1998) examine highly leveraged firms in order to evaluate the impact of pure financial distress, which they defined as either defaulting on a debt payment or attempting to restructure its debt because of difficulty making a debt payments. While economic and financial distress is always difficult to entangle, their focus on very highly leveraged firms helps to isolate firms in which leverage was a critical factor in their difficulties making payments rather than their simply no longer being viable economic units, as in many prior studies of the impact of bankruptcy. In their sample, all of the firms had positive operating margins when they became distress, and these margins typically exceed their industry median. Even more strikingly, the median distressed firm in their sample had earnings of nearly 4 times the median interest expense for their industry. Moreover, they find that the onset of financial distress is generally delayed by the fact that firms in their sample generally out performed their industry and their industry perfomrance improved relative to the prior year. For these reasons, Andrade and Kaplan conclude that they have isolated "a sample of firms for whom leverage is the primary if the not the sole source of financial distress" (p. 1457). They find that firms that experienced financial distress lost 10 to 20 percent of their market value. They also found that operating and net cash flow margins declined between 10 and 15 percent while the firms were distressed.

Opler and Titman (1994) take a somewhat different tack in trying to distinguish isolate

\footnotetext{
${ }^{28}$ See Altman (1984), Ang et al (1982), Warner (1977) and Weiss (1990).
} 
the impact of financial distress from economic distress by looking at the interaction of economic and financial distress. They look at industries which have had a negative economic shock, which they define as a 3-digit SIC industry with negative sales growth and a median stock return below $-30 \%$. They examine the differential response of firms within the industry based upon their degree of leverage. They found that firms with high leverage ratios performed substantially worse with, firms in the highest decile of leverage having $25 \%$ lower sales growth. As a result, these more highly leveraged firms lost market share.

There is considerable microeconomic evidence that also shows a strong statistical relationship between productivity and changes in asset values. Maksimovic and Phillips (1998) is perhaps the most comprehensive study that studies the impact of the financial distress associated with filing for bankruptcy (Chapter 11). They analyze 1195 manufacturing plants of 302 firms that filed for Chapter 11 between 1977 and 1990, and a control group of over 50,000 plants of non-bankrupt firms. They compared plant-level productivity in the financially distressed firms to TFP all firms, and also to TFP across industry groups that differ by varying levels of financial distress associated with demand shocks. ${ }^{29}$ For these industry groups, the lowest industry grouping consisted of those that were significantly distressed (very negative long-run demand shocks associated with long-run declining industries), and the highest industry grouping consisted of those were not distressed (very positive demand shocks associated with rapidly expanding industries). They found that TFP was low in the financially distressed firms, and systematically higher in firms that were in expanding industries, indicating that financial distress is associated with low TFP.

In particular, they found that TFP in distressed firms for the two years before filing for Chapter 11 was about 4.5 percent lower compared to all plants, and as much as 15 percent lower than plants in industries with the most positive demand shocks. During the first year of Chapter 11, the plants of distressed firms had productivity that was 9 percent below all firms, and almost 19 percent below those in industries with the most positive demand shocks. Three years after entering Chapter 11 the productivity of the plants of distressed firms was almost 37 percent below those in the industries with positive demand shocks. Productivity continued to be low after leaving Chapter 11. Relative to all firms, the plants of firms exiting Chapter 11 had productivity that was about 9-16 percent lower 1-3 years after Chapter 11. Moreover, productivity was also very low for plants in firms which were not bankrupt but were experiencing considerable financial distress. Specifically, the productivity in the lowest quartile of these shocks was not very different from the productivity in the plants of bankrupt firms.

\footnotetext{
${ }^{29} \mathrm{TFP}$ is adjusted for variation in capacity utilization.
} 
Regarding models that connect financial shocks to firm performance, Kyotaki and Moore (1997), Bernanke and Gertler (1989), and Carlstom and Fuerst (1997) develop models in a decline in asset values values reduce inputs and output through a net worth constraint Chari, Kehoe and McGrattan (2006) shows how disturbances to the efficient mix of inputs resulting from a financial shock reduces TFP in this class of models.

There are other channels through which a decline in asset values could lower TFP. If a decline in stock prices signals a greater likelihood that the firm would fail or contract in size, agency frictions within the firm would rise, which would tend to reduce output and productivity. This channel follows from the classic Folk theorem results in games of incomplete information (e.g. Fudenberg, Levine and Maskin). In addition, there is a class of models that formalize how agency and other informational frictions within the firm evolve over time, including Albuquerque and Hopenhayn 1997, Cooley, Marimon and Quadrini (2003), and Atkeson and Cole (2006). In all of these models, any factor that reduces the expected duration of the relationship between the principal and the agent, such as a decline in the share price, exacerbates the importance of the agency friction. The increases in these frictions lead to increases in monitoring costs, inefficient rent-seeking, diversion of investments to less efficient uses, and a an increased difficulty in generating optimal choices of privately observed actions, such as effort. All of these effects would reduce measured TFP and output. 


\section{Tables}

Table 1: Sample Statistics: Log Deviation of Output (Y) and Log change in Deflator ${ }^{30}$

\begin{tabular}{|c|c|c|c|c|c|}
\hline \multirow{2}{*}{ Year } & \multicolumn{2}{|c|}{ Mean } & \multicolumn{2}{|c|}{ Idiosyncratic Share } & Correlation \\
\cline { 2 - 5 } & $\mathbf{Y}$ & $\boldsymbol{\pi}$ & $\mathbf{Y}$ & $\boldsymbol{\pi}$ & $\mathbf{Y}$ and $\boldsymbol{\pi}$ \\
\hline 1930 & 0.00 & -0.05 & 0.99 & 0.35 & -0.27 \\
\hline 1931 & -0.06 & -0.07 & 0.61 & 0.13 & -0.27 \\
\hline 1932 & -0.10 & -0.05 & 0.55 & 0.46 & 0.54 \\
\hline 1933 & -0.08 & -0.02 & 0.70 & 0.75 & 0.29 \\
\hline 1934 & -0.04 & 0.00 & 0.92 & 1.00 & 0.05 \\
\hline 1935 & 0.00 & 0.01 & 1.00 & 0.92 & 0.40 \\
\hline 1936 & 0.04 & 0.03 & 0.91 & 0.62 & -0.14 \\
\hline 1937 & 0.11 & 0.06 & 0.66 & 0.47 & -0.12 \\
\hline
\end{tabular}

\footnotetext{
${ }^{30}$ Output is measured as the $\log$ deviation from $1929, \pi$ is the annual log change in the deflator, the idiosyncratic share is the fraction of the change in the variable accounted for by the non-mean component.
} 
Table 2: Output (Y) and Deflator $(\pi)$ in 1932

(Cumulative Log Change from 1929)

\begin{tabular}{|l|r|c|}
\hline Country & $\mathbf{Y}$ & \multicolumn{1}{|c|}{} \\
\hline \hline Australia & -0.07 & -0.28 \\
\hline U.S. & -0.30 & -0.27 \\
\hline Italy & -0.08 & -0.24 \\
\hline Hungary & -0.04 & -0.23 \\
\hline Japan & 0.05 & -0.22 \\
\hline Netherlands & -0.08 & -0.20 \\
\hline Germany & -0.28 & -0.19 \\
\hline Canada & -0.29 & -0.18 \\
\hline Denmark & 0.04 & -0.17 \\
\hline Finland & -0.04 & -0.17 \\
\hline Switzerland & -0.04 & -0.17 \\
\hline Sweden & -0.04 & -0.15 \\
\hline Norway & 0.01 & -0.12 \\
\hline Czech. & -0.11 & -0.08 \\
\hline U.K. & -0.06 & -0.08 \\
\hline Austria & -0.22 & -0.02 \\
\hline France & -0.11 & -0.02 \\
\hline \hline Mean & -0.10 & -0.16 \\
\hline Idiosyncratic Share & 0.55 & 0.18 \\
\hline
\end{tabular}


Table 3: Sample Statistics: Real Wages

Data are log deviations from 1929 values

\begin{tabular}{|c|c|c|}
\hline & & Correlation \\
\hline Year & Mean & with Y \\
\hline 1930 & 0.05 & 0.45 \\
\hline 1931 & 0.09 & 0.48 \\
\hline 1932 & 0.09 & 0.30 \\
\hline 1933 & 0.10 & 0.28 \\
\hline 1934 & 0.09 & -0.07 \\
\hline 1935 & 0.01 & 0.09 \\
\hline 1936 & 0.08 & -0.45 \\
\hline 1937 & 0.07 & -0.70 \\
\hline
\end{tabular}

Table 4: Benchmark Parameters

\begin{tabular}{|c|c|c|c|c|c|c|}
\hline$\theta$ & $\boldsymbol{\beta}$ & $\sigma$ & $\boldsymbol{\delta}$ & $\boldsymbol{\alpha}$ & $\boldsymbol{\rho}_{\mathbf{z}}$ & $\boldsymbol{\rho}_{\boldsymbol{\tau}}$ \\
\hline .33 & .95 & .92 & .07 & .5 & .80 & .00 \\
\hline
\end{tabular}

Table 5: Impact of a 10 Percent Deflation on Labor for Different Values of the Nonneutrality Parameter $(\eta)$

\begin{tabular}{|c|c|}
\hline $\boldsymbol{\eta}$ & Labor \\
\hline 0 & $-12.5 \%$ \\
\hline-0.25 & $-10.9 \%$ \\
\hline-0.50 & $-8.7 \%$ \\
\hline-0.75 & $-5.4 \%$ \\
\hline-0.90 & $-2.6 \%$ \\
\hline-1.00 & $-0.0 \%$ \\
\hline
\end{tabular}


Table 6. Model and Data Comparisons:

\section{for Different Nonneutralitiy Values $(\eta)$}

\begin{tabular}{|c|c|c|c|c|c|c|}
\hline Variable to be Explained & $\eta=$ & $\eta=$ & $\eta=$ & $\eta=$ & $\eta=$ & $\boldsymbol{\eta}=$ \\
& $\mathbf{0 . 0 0}$ & -.25 & -.50 & -.75 & -.90 & $-\mathbf{1 . 0 0}$ \\
\hline & \multicolumn{7}{|c|}{ Percentage of Data Explained by Model } \\
\hline TFP & 77 & 81 & 86 & 90 & 87 & 74 \\
\hline Aggregate Labor & 70 & 74 & 77 & 77 & 67 & 47 \\
\hline Consumption & 66 & 67 & 69 & 70 & 71 & 73 \\
\hline & \multicolumn{7}{|c|}{ Correlation Between Model and Data } \\
\hline Money Demand Shocks & 0.76 & 0.76 & 0.76 & 0.77 & 0.77 & 0.78 \\
\hline
\end{tabular}

Table 7. Comparing Industrial Wage Data to Model Wage

(Right panel adjusted for compositional change, left panel unadjusted) ${ }^{31}$

\begin{tabular}{|c|c|c|c|c|}
\hline \multirow{2}{*}{ Year } & \multicolumn{2}{|c|}{ Model $w$} & \multicolumn{2}{c|}{ Adj. Model $w$} \\
\cline { 2 - 5 } & mean & correlation & mean & correlation \\
\hline 1930 & 0.03 & 0.73 & 0.04 & 0.72 \\
\hline 1931 & 0.02 & 0.59 & 0.06 & 0.61 \\
\hline 1932 & -0.02 & 0.53 & 0.02 & 0.59 \\
\hline 1933 & -0.04 & 0.49 & -0.02 & 0.66 \\
\hline
\end{tabular}

\footnotetext{
${ }^{31}$ We adjusted wages according to

$$
w^{*}=w-.49 * u,
$$
}

where $u$ was our proxy for unemployment which is simply minus employment. 
Table 8. Output (Y) and Price Level (P) Decomposition Bounds

Percentage of Variation Explained by Money and Productivity Shocks

\begin{tabular}{|l|l|l|l|l|l|l|l|l|l|l|}
\hline & \multicolumn{2}{|c|}{$\eta=.00$} & \multicolumn{1}{c|}{$\eta=-.25$} & \multicolumn{2}{c|}{$\eta=-.50$} & \multicolumn{2}{c|}{$\eta=-.75$} & \multicolumn{2}{c|}{$\eta=-.90$} \\
\hline Variable & $\mathbf{Y}$ & $\mathbf{P}$ & $\mathbf{Y}$ & $\mathbf{P}$ & $\mathbf{Y}$ & $\mathbf{P}$ & $\mathbf{Y}$ & $\mathbf{P}$ & $\mathbf{Y}$ & $\mathbf{P}$ \\
\hline$\varepsilon_{\tau}$ & $48 \%$ & $94 \%$ & $46 \%$ & $94 \%$ & $41 \%$ & $93 \%$ & $29 \%$ & $91 \%$ & $15 \%$ & $89 \%$ \\
\hline$\varepsilon_{z}$ & $68 \%$ & $<0 \%$ & $75 \%$ & $<0 \%$ & $84 \%$ & $<0 \%$ & $94 \%$ & $<0 \%$ & $99 \%$ & $<0 \%$ \\
\hline$\varepsilon_{\tau}-\operatorname{cov}\left(\varepsilon_{z}, \varepsilon_{\tau}\right)$ & $49 \%$ & $94 \%$ & $44 \%$ & $95 \%$ & $37 \%$ & $96 \%$ & $25 \%$ & $97 \%$ & $12 \%$ & $96 \%$ \\
\hline$\varepsilon_{z}-\operatorname{cov}\left(\varepsilon_{z}, \varepsilon_{\tau}\right)$ & $68 \%$ & $<0 \%$ & $74 \%$ & $<0 \%$ & $80 \%$ & $<0 \%$ & $88 \%$ & $<0 \%$ & $89 \%$ & $<0 \%$ \\
\hline $\operatorname{corr}\left(\varepsilon_{z}, \varepsilon_{\tau}\right)$ & \multicolumn{1}{|c|}{0.08} & \multicolumn{1}{|c|}{0.15} & \multicolumn{1}{c|}{0.24} & \multicolumn{1}{c|}{0.38} & \multicolumn{1}{c|}{0.48} \\
\hline
\end{tabular}

Table 9: Statistical Summary of the Shocks with benchmark nonneutrality $(\eta=-0.50)$

\begin{tabular}{|c|c|c|c|c|c|}
\hline & \multicolumn{2}{|c|}{$\boldsymbol{\varepsilon}_{z}$} & \multicolumn{2}{|c|}{$\boldsymbol{\varepsilon}_{\tau}$} & \\
\hline Year & Mean & $\begin{array}{c}\text { Idiosyncratic } \\
\text { Share }\end{array}$ & Mean & $\begin{array}{c}\text { Idiosyncratic } \\
\text { Share }\end{array}$ & $\begin{array}{c}\text { Correlation } \\
\boldsymbol{\varepsilon}_{z} \& \varepsilon_{\tau}\end{array}$ \\
\hline 1930 & 0.02 & 0.81 & -0.04 & 0.33 & -0.24 \\
\hline 1931 & -0.02 & 0.77 & -0.09 & 0.08 & 0.03 \\
\hline 1932 & -0.03 & 0.44 & -0.07 & 0.37 & 0.27 \\
\hline 1933 & -0.01 & 0.94 & -0.03 & 0.68 & 0.28 \\
\hline
\end{tabular}


Table 10: $R^{2}$ - Productivity Innovations Regressed on Macro Variables Cross-Country Depression Data versus Postwar U.S. Data

\begin{tabular}{|l|c|l|}
\hline Independent Variable & $R^{2}$ - Depression & $R^{2}-$ Postwar US \\
\hline Change in Log Deflator & 0.01 & 0.02 \\
\hline Nominal Interest Rate & 0.02 & 0.11 \\
\hline Real Interest Rate & 0.02 & 0.10 \\
\hline Real Exchange Rate & 0.05 & 0.11 \\
\hline M0 & 0.01 & 0.01 \\
\hline M1 & 0.23 & 0.01 \\
\hline M1-M0 & 0.08 & 0.01 \\
\hline Bernanke-James Bank Variable & 0.19 & NA \\
\hline Real Stock Price & $\mathbf{0 . 4 0}$ & $\mathbf{0 . 0 5}$ \\
\hline
\end{tabular}




\section{Appendix Tables}

\begin{tabular}{|c|c|c|c|c||c|c|c|c|}
\hline \multicolumn{7}{|c|}{ Table A1: Log Deviations in Output and Productivity } \\
\hline & Output & & & & Productivity & & & \\
\hline Country & $\mathbf{1 9 3 0}$ & $\mathbf{1 9 3 1}$ & $\mathbf{1 9 3 2}$ & $\mathbf{1 9 3 3}$ & $\mathbf{1 9 3 0}$ & $\mathbf{1 9 3 1}$ & $\mathbf{1 9 3 2}$ & $\mathbf{1 9 3 3}$ \\
\hline Australia & 0.01 & -0.08 & -0.07 & -0.01 & $0.05^{*}$ & $0.01^{*}$ & $0.03^{*}$ & $0.04^{*}$ \\
\hline Canada & -0.05 & -0.18 & -0.29 & -0.36 & -0.03 & -0.13 & -0.18 & -0.22 \\
\hline France & -0.01 & -0.06 & -0.11 & -0.09 & 0.00 & -0.06 & -0.10 & -0.08 \\
\hline Germany & -0.07 & -0.20 & -0.28 & -0.20 & -0.03 & -0.07 & -0.07 & -0.03 \\
\hline Japan & 0.01 & 0.04 & 0.05 & 0.09 & $0.00^{*}$ & $0.06^{*}$ & $0.06^{*}$ & $0.08^{*}$ \\
\hline U.K & 0.00 & -0.05 & -0.06 & -0.04 & 0.01 & -0.03 & -0.03 & -0.04 \\
\hline U.S. & -0.09 & -0.15 & -0.30 & -0.31 & -0.06 & -0.09 & -0.18 & -0.20 \\
\hline
\end{tabular}

\begin{tabular}{|c|c|c|c|c|}
\hline \multicolumn{5}{|c|}{ Table A2: Log TFP Deviations from 1929} \\
\hline & \multicolumn{4}{|c|}{ Model $(\eta=-0.50)$} \\
\hline Country & $\mathbf{1 9 3 0}$ & $\mathbf{1 9 3 1}$ & $\mathbf{1 9 3 2}$ & $\mathbf{1 9 3 3}$ \\
\hline Canada & -0.02 & -0.09 & -0.14 & -0.21 \\
\hline France & 0.01 & -0.01 & -0.05 & 0.00 \\
\hline Germany & -0.04 & -0.10 & -0.12 & -0.10 \\
\hline U.K. & 0.00 & -0.02 & -0.02 & -0.02 \\
\hline U.S. & -0.04 & -0.05 & -0.13 & -0.17 \\
\hline
\end{tabular}

\footnotetext{
${ }^{32}$ The productivity measure is labor productivity if the variable has an "** and total factor productivity otherwise.
} 
Table A3. Sample Statistics for Industrial Production and Industrial Wages Deflated by Producer Price Index ${ }^{33}$

\begin{tabular}{|c|c|c|c|c|}
\hline \multirow{2}{*}{ Year } & \multicolumn{2}{|c|}{ Correlations } & Country-Specific Component \\
\cline { 2 - 5 } & IP \& W/WPI & IP \& W/CPI & IP & W /PPI \\
\hline 1930 & 0.14 & 0.21 & 0.64 & 0.18 \\
\hline 1931 & 0.12 & 0.15 & 0.24 & 0.23 \\
\hline 1932 & -0.28 & 0.07 & 0.29 & 0.41 \\
\hline 1933 & -0.20 & 0.35 & 0.50 & 0.42 \\
\hline 1934 & -0.43 & -0.05 & 0.73 & 0.56 \\
\hline 1935 & -0.28 & 0.00 & 0.95 & 0.99 \\
\hline 1936 & -0.72 & -0.38 & 0.95 & 0.73 \\
\hline 1937 & -0.88 & -0.56 & 0.59 & 0.94 \\
\hline
\end{tabular}

\footnotetext{
${ }^{33}$ The following countries are not included for some or all years due to data availability: Switzerland for all years, Austria from 1935 onwards, and Czechoslovakia in 1937.
} 
Table A4. Composition of Wholesale Price Index ${ }^{34}$

\begin{tabular}{|c|c|c|c|c|}
\hline Country & Food \& Ag. & Min., Met. \& Energy & Ind. Prods. & Misc. \\
\hline Australia & 0.637 & 0.132 & 0.231 & 0 \\
\hline Austria & 0.691 & 0.309 & 0 & 0 \\
\hline Canada & 0.337 & 0.296 & 0.367 & 0 \\
\hline Czechoslovakia & 0.325 & 0.458 & 0.216 & 0 \\
\hline Denmark & 0.385 & 0.615 & 0 & 0 \\
\hline Finland & 0.496 & 0 & 0.313 & .192 \\
\hline France & 0.444 & 0.156 & .4 & 0 \\
\hline Germany & 0.28 & 0.41 & 0.13 & 0.18 \\
\hline Hungary & 0.444 & 0.192 & 0.23 & 0.134 \\
\hline Italy & 0.431 & 0.157 & 0.412 & 0 \\
\hline Japan & 0.268 & 0.089 & 0.482 & 0.161 \\
\hline Netherlands & 0.583 & 0 & 0 & 0.417 \\
\hline Norway & 0.546 & 0.177 & 0.257 & 0.02 \\
\hline Sweden & 0.496 & 0.16 & 0.319 & 0 \\
\hline Switzerland & 0.167 & 0 & 0.333 & 0.5 \\
\hline
\end{tabular}

\footnotetext{
${ }^{34}$ All numbers are from various years of the League of Nations' Statistical Yearbook
} 
Table A5. Composition of Industrial Production ${ }^{35}$

\begin{tabular}{|c|c|c|c|c|}
\hline Country & Food \& Ag. & Mining, Metals \& Energy & Manufacturing & Misc. \\
\hline Canada & 0.323 & 0.291 & 0.367 & 0 \\
\hline Czechoslovakia & 0.07 & 0.2 & 0.73 & 0 \\
\hline Denmark & 0.408 & 0.38 & 0.212 & 0 \\
\hline France & 0 & 0.07 & 0.43 & 0.5 \\
\hline Germany & 0.15 & 0.232 & 0.606 & \\
\hline Hungary & 0.256 & 0.235 & 0.509 & 0.134 \\
\hline Norway & 0.371 & 0.236 & 0.393 & \\
\hline Sweden & 0.359 & 0.35 & 0.291 & 0 \\
\hline
\end{tabular}

\footnotetext{
${ }^{35}$ All numbers are from various years of the League of Nations' Statistical Yearbook
} 
Figure 1. Data on Output and Productivity 1930-33

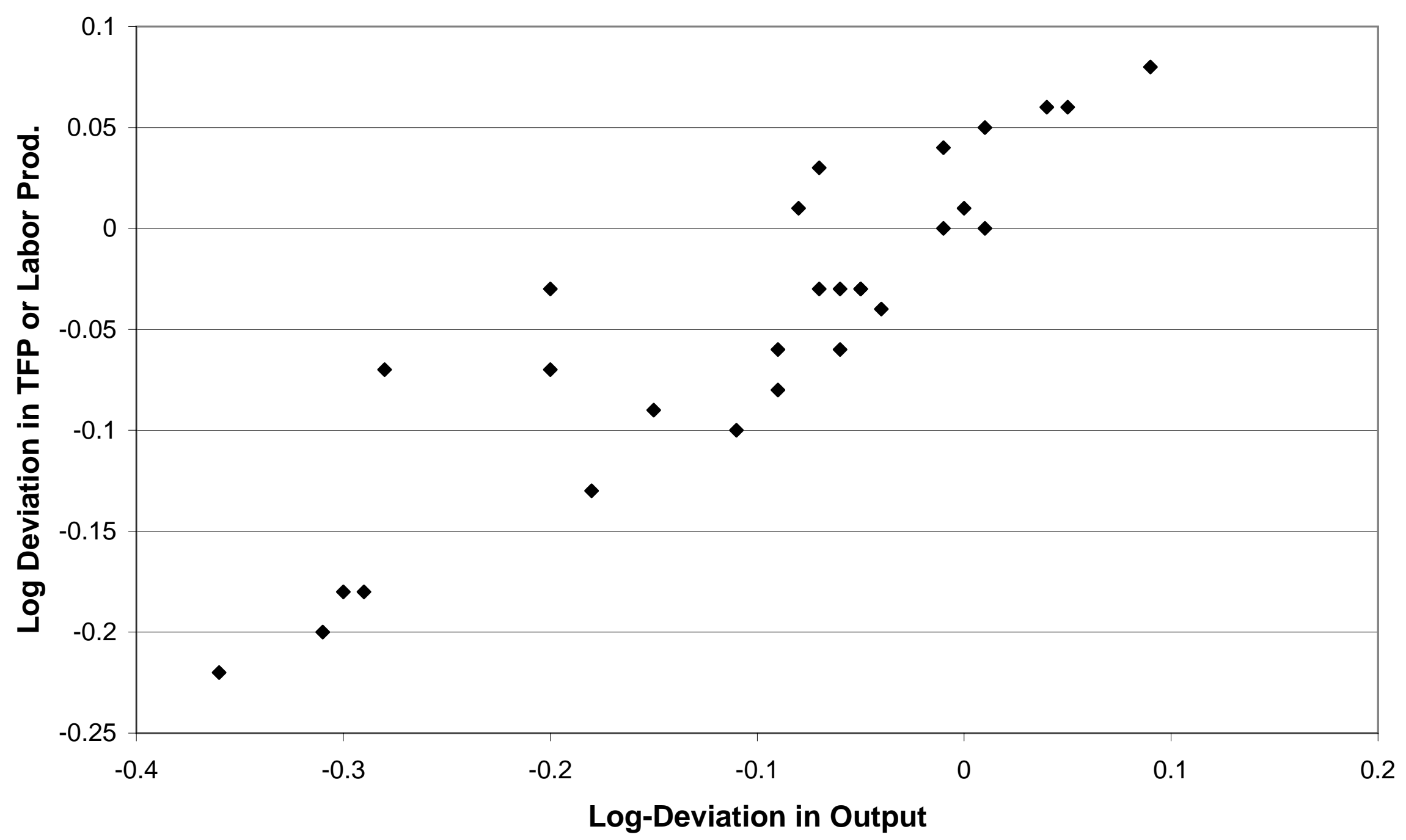


Figure 2: Total Factor Productivity: Data vs. Model

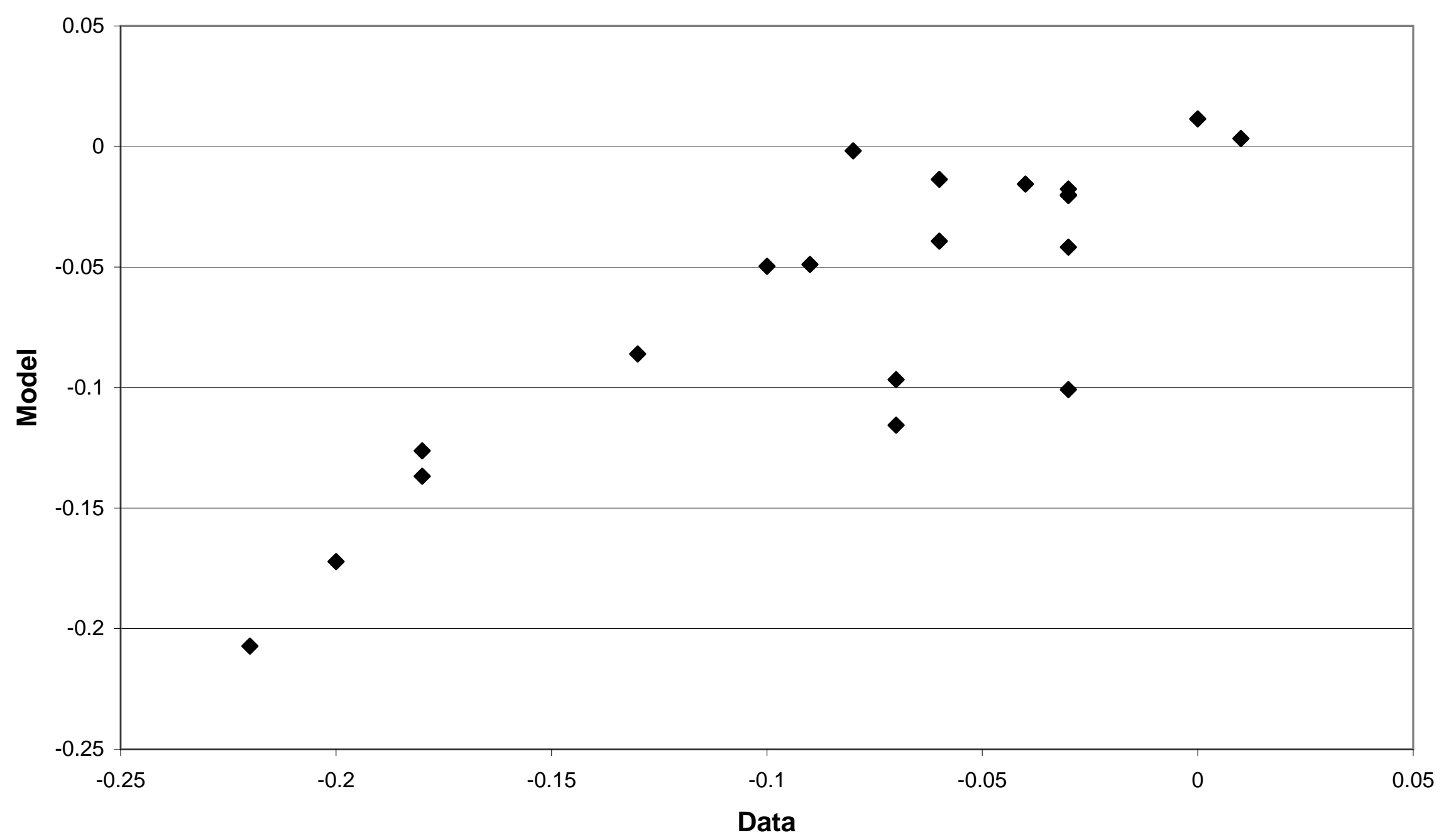


Figure 3: Money Demand Shocks: Model vs Data

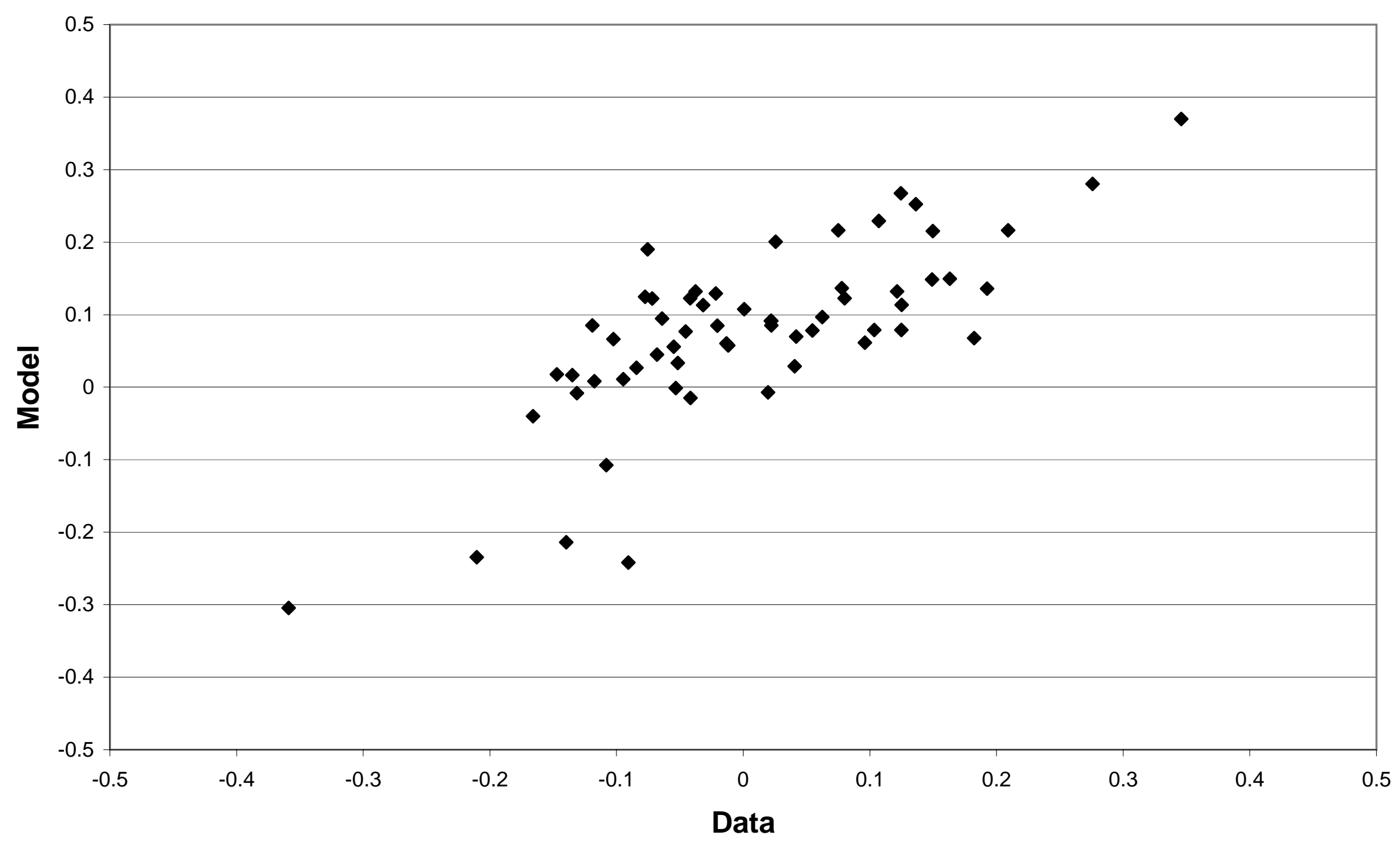

